\title{
Interpreting Instructional Cues in Task Switching Procedures: The Role of Mediator Retrieval
}

\author{
Gordon D. Logan and Darryl W. Schneider \\ Vanderbilt University
}

\begin{abstract}
In 3 experiments the role of mediators in task switching with transparent and nontransparent cues was examined. Subjects switched between magnitude (greater or less than 5) and parity (odd or even) judgments of single digits. A cue-target congruency effect indicated mediator use: subjects responded faster to congruent cue-target combinations (e.g., $O D D-3$ ) than to incongruent cue-target combinations (e.g., $O D D-4)$. Experiment 1 revealed significant congruency effects with transparent word cues $(O D D$, EVEN, $H I G H$, and $L O W)$ and with relatively transparent letter cues $(O, E, H$, and $L)$ but not with nontransparent letter cues $(D, V, G$, and $W)$. Experiment 2 revealed significant congruency effects after subjects who were trained with nontransparent letter cues were informed of the relations between cues and word mediators halfway through the experiment. Experiment 3 showed that congruency effects with relatively transparent letter cues diminished over 10 sessions of practice, suggesting that subjects used mediators less as practice progressed. The results are discussed in terms of the role of mediators in interpreting instructional cues.
\end{abstract}

Keywords: task switching, mediator retrieval, instructional cues, executive control

Executive control is an important topic in many areas of psychology and neuroscience because it highlights the inherent flexibility of human minds, showcasing their ability to adapt to new goals and tasks on a moment's notice. Task switching experiments have become a popular way to investigate executive control because they require subjects to alternate rapidly between different courses of thought and action. Switching from one task to another produces robust increases in reaction time (RT) and reductions in accuracy, known as switch costs, that are easy to replicate and appear in a variety of task switching procedures (for reviews, see Logan, 2003; Monsell, 2003). The present article focuses on an important but often neglected aspect of task switching performance: the processes by which subjects interpret the instructions that tell them to do one task or another. In most task switching procedures, the instructions are given at the beginning of the experiment or at the beginning of a block of trials, so the processes by which the instructions are interpreted may be finished by the time the first response is collected. The explicit task-cuing procedure differs from the rest in this respect. An instructional cue is given on each trial, just before the target stimulus appears, so the processes by which subjects understand the instruction may be reflected in RT and accuracy data. Indeed, recent studies in our laboratory suggest that switch costs in the explicit task-cuing procedure are more likely to reflect the processes involved in

Gordon D. Logan and Darryl W. Schneider, Department of Psychology, Vanderbilt University.

This research was supported by National Science Foundation Grant BCS 0133202. We are grateful to Julie Delheimer for testing the subjects.

Correspondence concerning this article should be addressed to Gordon D. Logan or Darryl W. Schneider, Department of Psychology, Vanderbilt University, Nashville TN 37203. E-mail: gordon.logan@vanderbilt.edu or darryl.schneider@vanderbilt.edu interpreting instructional cues than other executive processes, such as switching task sets (Arrington \& Logan, 2004b; Logan \& Bundesen, 2003, 2004; Logan \& Schneider, in press; Schneider \& Logan, 2005, in press). The present article extends that line of research by attempting to specify the processes involved in cue interpretation in greater detail.

The present experiments addressed the interpretation of instructional cues by focusing on the contrast between transparent or meaningful cues, whose conventional meanings specify the tasks to be performed (e.g., High-Low is a transparent cue for magnitude judgments), and nontransparent or arbitrary cues, whose conventional meanings are unrelated to the tasks to be performed (e.g., $G$ may be an arbitrary cue for magnitude judgments). Several studies have shown that transparent cues produce smaller switch costs than nontransparent cues (Arbuthnott \& Woodward, 2002; Logan \& Bundesen, 2004; Mayr \& Kliegl, 2000; Miyake, Emerson, Padilla, \& Ahn, 2004). The present investigation attempted to distinguish between two explanations of the difference in switch costs between transparent and nontransparent cues: association strength and mediated retrieval.

The association strength hypothesis is illustrated in the top panel of Figure 1. It assumes that transparent and nontransparent cues are associated directly with task sets or task goals without intersecting each other. Associations between transparent cues and task sets or goals are stronger than associations between nontransparent cues and task sets or goals, so the task sets or goals can be retrieved more quickly. Retrieval is required when tasks change but not when they repeat, so switch costs are smaller with transparent cues than with nontransparent cues. The mediated retrieval hypothesis is illustrated in the bottom panel of Figure 1. It assumes that transparent cues are associated directly with task sets or goals but that nontransparent cues are not. Instead, nontransparent cues are associated directly with transparent cues. Transparent cues mediate the pathway from nontransparent cues to task sets or 


\section{Association Strength}

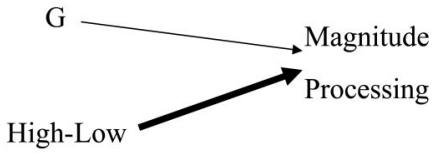

\section{Mediated Retrieval}

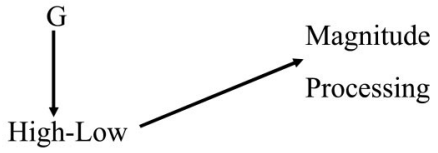

Figure 1. Illustration of association strength and mediated retrieval explanations of the relation between nontransparent and transparent cues. $G$ is a nontransparent cue; High-Low is a transparent cue; and Magnitude Processing is the goal, task set, or process indicated by the cues. The association strength hypothesis assumes direct associations between each of the cues and magnitude processing, but association strength is greater for transparent cues (indicated by the thickness of the arrow). The mediated retrieval hypothesis assumes that transparent cues are associated directly with magnitude processing, but nontransparent cues are associated indirectly, with transparent cues mediating the pathway.

goals. Nontransparent cues require an extra step-mediator retrieval-that is not required for transparent cues. Switch costs are smaller with transparent cues because they do not require mediator retrieval.

We have drawn the contrast between the association strength hypothesis and the mediated retrieval hypothesis more sharply than some researchers have drawn it in the literature. Arbuthnott and Woodward (2002) explicitly adopted the association strength hypothesis, and Logan and Bundesen (2004) explicitly adopted mediated retrieval. Mayr and Kliegl (2000) and Miyake et al. (2004) fell between these extremes, with Mayr and Kliegl closer to Logan and Bundesen (2004) and Miyake et al. closer to Arbuthnott and Woodward. The researchers also differ in their assumptions about what happens after a cue is interpreted, so more is at stake in contrasts between researchers than their assumptions about cue encoding. We leave these differences aside until the General Discussion section and focus for now on the simpler and sharper contrast between association strength and mediated retrieval as explanations of cue interpretation.

\section{Distinguishing Mediated Retrieval From Association Strength}

There is a clear theoretical distinction between the mediated retrieval hypothesis and the association strength hypothesis: The mediated retrieval hypothesis assumes that nontransparent cues and transparent cues share a common pathway. Subjects must retrieve a mediator that is somehow equivalent to a transparent cue and then use that mediator to retrieve the task set or goal in the same way they would use the transparent cue. Association strength assumes that nontransparent cues and transparent cues follow different pathways, each leading directly from the cue to the task set or goal, but with different strengths. A clear empirical distinc- tion between mediated retrieval and association strength is also possible: Mediated retrieval predicts that nontransparent cues will evoke a mediator that behaves like a transparent cue; association strength predicts that nontransparent cues will not evoke a mediator. The difficulty lies in developing empirical criteria for determining whether subjects use mediators and identifying what those mediators may be.

If subjects use mediators, then it should be possible to induce them to use particular mediators that would have diagnostic effects on RT and accuracy. To this end, we exploited a cue-target congruency effect that was discovered by Schneider and Logan (2005). They had subjects switch between magnitude (greater or less than 5) and parity (odd or even) judgments of single digits and used the word $H I G H$ or the word $L O W$ to cue the magnitude task and the word $O D D$ or the word EVEN to cue the parity task. They found that RT was faster and accuracy was higher when cues and targets were congruent (e.g., $O D D-3$ ) than when cues and targets were incongruent (e.g., $O D D-4)$. In the present experiments, we had subjects perform parity and magnitude judgments on single digits and we tried to induce subjects to retrieve the words odd, even, high, and low as mediators in response to nontransparent cues. We expected to find a cue-target congruency effect if they retrieved these words and not to find an effect if they did not retrieve them. Finding the effect with nontransparent cues would support the mediator retrieval hypothesis; failing to find the effect with nontransparent cues would support the association strength hypothesis or suggest that subjects used some other mediator (e.g., a mediator not corresponding to a response category).

Our first experiment manipulated the likelihood that subjects would use these words as mediators by varying the transparency of the cues. One group received the words $O D D, E V E N, H I G H$, and $L O W$ as cues. Subjects in this word cue group should replicate the cue-target congruency effect observed by Schneider and Logan (2005). A second group received the letters $O, E, H$, and $L$ as cues. These cues are the first letters of the words odd, even, high, and low, so the relation between the words and cues should be relatively transparent. Subjects in this letter1 cue group should be likely to use the words as mediators and so should be likely to show a cue-target congruency effect that is similar to that found in the word cue group. The third group received the letters $D, V, G$, and $W$ as cues. These cues are the second or third letters of the words odd, even, high, and low, so the relation between the words and the cues should be less transparent than the relation with first-letter cues. Subjects in this letter23 cue group should be less likely to use the words as mediators and so should be less likely to show a cue-target congruency effect like the one found in the word cue group.

In the second experiment we attempted to induce the use of the words odd, even, high, and low as mediators by informing subjects who were trained with the letter 23 cues of the relation between the letter cues and the words halfway through the experiment. In the third experiment we attempted to determine whether subjects abandon these word mediators in favor of direct associations between cues, targets, and responses after extensive practice with the letter 1 cues.

Each experiment used two cues for each task-four cues in total-in order to separate cue encoding benefits from other factors contributing to switch costs. Until recently, most experiments with explicit task cuing used one cue for each task, confounding cue 
repetition with task repetition (cues repeated whenever tasks repeated; cues changed whenever tasks changed). This confound between cue repetition and task repetition can be removed by using two cues for each task. This results in three transitions across trials: cue repetitions, in which the cue and the task both repeat (e.g., $O D D \rightarrow O D D)$, task repetitions, in which the cue changes but the task repeats (e.g., EVEN $\rightarrow O D D$ ), and task alternations, in which the cue and the task both change (e.g., $H I G H \rightarrow O D D)$. Experiments with two cues per task have shown faster RTs with cue repetitions than with task repetitions, suggesting that much of the traditional switch cost (task alternation RT minus cue repetition RT) is due to cue encoding benefits from repeated cues (Logan \& Bundesen, 2003; Mayr \& Kliegl, 2003). The difference between task repetitions and task alternations varies between experiments - sometimes it is small and sometimes it is large-and has been interpreted in various ways. Some interpret it as a "true switch cost" (Mayr \& Kliegl, 2003), some interpret it as priming from related cues (Logan \& Schneider, in press; Schneider \& Logan, 2005, in press), and some interpret it as facilitation from mediator repetition (Logan \& Bundesen, 2004). The present experiments were not designed to distinguish between these interpretations, though we endorse our previous interpretations in the General Discussion section.

\section{Experiment 1}

In the first experiment we looked for cue-target congruency effects in subjects trained with word cues (word group), with the first letters of the words as cues (letter1 group), and with the second or third letters of the words as cues (letter23 group). Cue-target congruency effects should occur if subjects use the words odd, even, high, and low as mediators. Thus, every subject in the word group should show a congruency effect, and subjects in the letter 1 and letter 23 groups who grasp the relations between the letter cues and the words should also show a congruency effect. The congruency effect should be stronger in the letter1 group than in the letter23 group because first-letter cues should be more transparent than second- and third-letter cues.

\section{Method}

Subjects. Sixty individuals from Vanderbilt University completed the experiment in exchange for partial course credit or monetary compensation. Twenty subjects were assigned to each cue group.

Apparatus and stimuli. The experiment was conducted on Dell Dimension computers controlled by E-Prime software. Stimuli were displayed on Sony Trinitron monitors, and responses were collected from standard QWERTY keyboards. Cues and target stimuli were displayed in white 24-point bold Courier New font on a black background. Cues for the word condition were the words $O D D(33 \times 11 \mathrm{~mm})$, EVEN $(44 \times 11 \mathrm{~mm})$, $H I G H(44 \times 11 \mathrm{~mm})$, and $\operatorname{LOW}(33 \times 11 \mathrm{~mm})$. Cues for the letter 1 condition were the letters $O, E, H$, and $L$ (each $10 \times 11 \mathrm{~mm}$ ). Cues for the letter23 condition were the letters $D, V, G$, and $W$ (each $10 \times 11 \mathrm{~mm}$ ). Target stimuli were the digits $1,2,3,4,6,7,8$, and 9 (each $8 \times 11 \mathrm{~mm}$ ). Viewing distance was approximately $60 \mathrm{~cm}$, such that $1 \mathrm{~cm}$ of the display subtended about 1 degree of visual angle.

Procedure. After providing informed consent, subjects were seated in individual testing rooms and given instructions concerning the trial format, tasks, cues, target stimuli, and response-key mappings. Each subject received instructions for only one set of cues. Subjects in the letter1 and letter 23 conditions were not informed of the correspondence between the cues and the words. All subjects were instructed to respond quickly but with high accuracy on every trial.

The experiment was divided into blocks of 80 trials. After performing one practice block, subjects completed 12 experimental blocks (960 trials), with every two blocks representing a replication of a 4 (cue) $\times 8$ (target) $\times$ 5 (SOA: 0, 100, 300, 500, or $900 \mathrm{~ms}$ ) block design. The cue, target, and SOA on each trial within a block were randomly selected. Blocks were separated by optional rest periods.

Each trial began with the presentation of two white fixation crosses (each $10 \times 10 \mathrm{~mm}$ ), arranged vertically in the center of the screen (outer edges separated by $14 \mathrm{~mm}$ ). After $600 \mathrm{~ms}$, the top fixation cross disappeared and a cue appeared in its location. At a variable SOA after the onset of the cue, the bottom fixation cross disappeared and a target appeared in its location. The cue and the target remained on screen until the subject responded by pressing the $F$ key with his or her left index finger or the $J$ key with his or her right index finger. After a response, the screen was cleared and the next trial commenced after $300 \mathrm{~ms}$. The response and RT were recorded for every trial. Response categories for the same task were assigned to different response keys, and the four possible response-key mappings were counterbalanced across subjects. A reminder of the response-key mappings was posted below the display screen.

Following the experiment, which lasted about $50 \mathrm{~min}$, subjects in the letter1 and letter23 groups were asked the following questions: (a) Did you notice any associations between the letter cues and the tasks or responses? (b) Did you think that the letter cues were associated with specific words? (c) For the letter1 (letter23) condition: Did you think that $O(D)$ meant $O D D, E(V)$ meant EVEN, $H(G)$ meant $H I G H$, and $L(W)$ meant $L O W$ ? Subjects' responses were noted by the experimenter.

\section{Results and Discussion}

The first trial of each block and trials with RT exceeding 3,000 ms $(1.9 \%$ of trials $)$ were excluded from all analyses. Trials with incorrect responses (3.4\% of trials) were excluded from the RT analysis. The transition (cue repetition, task repetition, or task alternation) for each trial was determined post hoc based on the relationship between trials $n$ and $n-1$. Cue-target congruency was defined post hoc by examining the relation between the cue and the target on each trial. For the word group, congruency was based on the correspondence between the cues and the correct response to the target. For the letter 1 and letter 23 groups, cue-target congruency was based on the correspondence between the cues, the task-specific words, and the correct response to the target. For example, for the letter1 (letter23) group, $O(D)$ and 3 was a congruent trial and $E(V)$ and 3 was an incongruent trial. Mean RT and accuracy were calculated for each combination of cue group, transition, cue-target congruency, and SOA; these data are provided in Table 1 . The RT and accuracy data were submitted to separate 3 (cue group) $\times 3$ (transition) $\times 2$ (cue-target congruency) $\times 5$ (SOA) mixed-factors analyses of variance (ANOVAs), with cue group as a between-subjects factor and the other variables as within-subject factors. The summary tables for these ANOVAs are presented in Table 2. Accuracy was high, averaging 97\%, and there was no evidence of speed-accuracy trade-offs, so the analyses focus on RT.

The RT data showed standard effects that are commonly observed in the explicit task-cuing procedure. RT decreased significantly as SOA increased, reflecting the time course of cue encoding. RT was faster for cue repetitions $(M=808 \mathrm{~ms})$ than for task repetitions ( $M=930 \mathrm{~ms}$ ), reflecting a cue encoding benefit, and faster for task repetitions than for task alternations $(M=996 \mathrm{~ms})$, 
Table 1

Mean Reaction Time (RT; in Milliseconds) and Accuracy Across Subjects at Each Stimulus Onset Asynchrony (in Milliseconds) as a Function of Cue Group, Transition, and Cue-Target Congruency in Experiment 1

\begin{tabular}{|c|c|c|c|c|c|c|c|c|c|c|}
\hline \multirow{3}{*}{$\begin{array}{l}\text { Transition, cue-target } \\
\text { congruency, and measure }\end{array}$} & \multicolumn{10}{|c|}{ Stimulus onset asynchrony } \\
\hline & \multicolumn{2}{|c|}{0} & \multicolumn{2}{|c|}{100} & \multicolumn{2}{|c|}{300} & \multicolumn{2}{|c|}{500} & \multicolumn{2}{|c|}{900} \\
\hline & $M$ & $S E$ & $M$ & $S E$ & $M$ & $S E$ & $M$ & $S E$ & $M$ & $S E$ \\
\hline \multicolumn{11}{|c|}{ Cue group: word } \\
\hline \multicolumn{11}{|l|}{ Task alternation } \\
\hline \multicolumn{11}{|l|}{ Incongruent } \\
\hline $\mathrm{RT}$ & 1,225 & 46 & 1,116 & 44 & 1,002 & 44 & 917 & 44 & 845 & 39 \\
\hline Accuracy & 92.3 & 1.3 & 92.8 & 1.5 & 93.4 & 1.4 & 94.3 & 1.1 & 95.2 & 1.0 \\
\hline \multicolumn{11}{|l|}{ Congruent } \\
\hline $\mathrm{RT}$ & 1,088 & 44 & 1,000 & 44 & 898 & 43 & 822 & 44 & 782 & 42 \\
\hline Accuracy & 96.9 & 0.8 & 95.8 & 1.0 & 95.7 & 1.0 & 96.7 & 0.9 & 97.0 & 0.7 \\
\hline \multicolumn{11}{|l|}{ Task repetition } \\
\hline \multicolumn{11}{|l|}{ Incongruent } \\
\hline $\mathrm{RT}$ & 1,138 & 44 & 1,097 & 46 & 910 & 44 & 871 & 45 & 807 & 42 \\
\hline Accuracy & 94.6 & 1.4 & 95.3 & 1.7 & 94.3 & 1.4 & 97.0 & 0.9 & 96.1 & 1.0 \\
\hline \multicolumn{11}{|l|}{ Congruent } \\
\hline RT & 987 & 47 & 908 & 44 & 819 & 45 & 767 & 37 & 743 & 38 \\
\hline Accuracy & 98.4 & 0.6 & 98.6 & 0.8 & 98.1 & 0.7 & 98.4 & 0.7 & 98.2 & 0.9 \\
\hline \multicolumn{11}{|l|}{ Cue repetition } \\
\hline \multicolumn{11}{|l|}{ Incongruent } \\
\hline RT & 1,008 & 36 & 899 & 36 & 797 & 34 & 753 & 35 & 762 & 35 \\
\hline Accuracy & 97.2 & 1.0 & 96.3 & 1.1 & 96.3 & 1.0 & 96.3 & 0.9 & 97.7 & 0.7 \\
\hline \multicolumn{11}{|l|}{ Congruent } \\
\hline $\mathrm{RT}$ & 926 & 38 & 826 & 33 & 765 & 34 & 730 & 35 & 696 & 30 \\
\hline Accuracy & 97.2 & 0.7 & 98.4 & 0.7 & 97.0 & 0.7 & 98.8 & 1.1 & 98.4 & 0.7 \\
\hline
\end{tabular}

Cue group: letter1

Task alternation ncongruen

RT

Accuracy

Congruent

RT

Accuracy

Task repetition

RT

Accuracy

Congruent

RT

Accuracy

Cue repetition

Incongruent

RT

Accuracy

Congruent

RT

Accuracy
Incongruent

$\begin{array}{cccccccccc}1,297 & 46 & 1,211 & 44 & 1,057 & 44 & 973 & 44 & 907 & 39 \\ 93.7 & 1.3 & 93.3 & 1.5 & 94.3 & 1.4 & 95.0 & 1.1 & 95.5 & 1.0 \\ & & & & & & & & & \\ 1,156 & 44 & 1,101 & 44 & 959 & 43 & 892 & 44 & 848 & 42 \\ 97.4 & 0.8 & 97.9 & 1.0 & 96.9 & 1.0 & 97.0 & 0.9 & 96.7 & 0.7\end{array}$

$\begin{array}{llllllllll}1,160 & 44 & 1,118 & 46 & 983 & 44 & 922 & 45 & 887 & 42 \\ 92.9 & 1.4 & 93.3 & 1.7 & 94.3 & 1.4 & 96.7 & 0.9 & 98.7 & 1.0\end{array}$

$\begin{array}{llllllllll}1,051 & 47 & 980 & 44 & 912 & 45 & 812 & 37 & 799 & 38\end{array}$

$\begin{array}{llllllllll}98.7 & 0.6 & 98.6 & 0.8 & 99.2 & 0.7 & 98.5 & 0.7 & 97.8 & 0.9\end{array}$

$\begin{array}{llllllllll}952 & 36 & 929 & 36 & 825 & 34 & 788 & 35 & 718 & 35\end{array}$

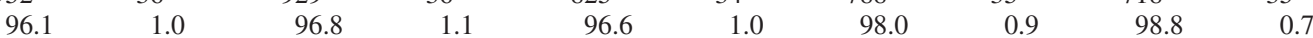

$\begin{array}{llllllllll}936 & 38 & 844 & 33 & 756 & 34 & 772 & 35 & 729 & 30\end{array}$

$\begin{array}{llllllllll}98.2 & 0.7 & 98.2 & 0.7 & 98.7 & 0.7 & 97.7 & 1.1 & 98.6 & 0.7\end{array}$

Cue group: letter23

Task alternation Incongruent

RT

Accuracy

Congruent

RT

Accuracy

Task repetition

Incongruent

RT

Accuracy

$\begin{array}{cccccccccc}1,183 & 46 & 1,071 & 44 & 952 & 44 & 900 & 44 & 815 & 39 \\ 95.0 & 1.3 & 95.7 & 1.5 & 94.7 & 1.4 & 95.3 & 1.1 & 95.5 & 1.0 \\ 1,159 & 44 & 1,070 & 44 & 918 & 43 & 875 & 44 & 825 & 42 \\ 95.9 & 0.8 & 95.9 & 1.0 & 97.5 & 1.0 & 96.6 & 0.9 & 97.2 & 0.7 \\ & & & & & & & & & \\ 1,098 & 44 & 1,018 & 46 & 927 & 44 & 829 & 45 & 785 & 42 \\ 96.2 & 1.4 & 93.6 & 1.7 & 96.9 & 1.4 & 98.0 & 0.9 & 95.9 & 1.0\end{array}$


Table 1 (continued)

\begin{tabular}{|c|c|c|c|c|c|c|c|c|c|c|}
\hline \multirow{3}{*}{$\begin{array}{l}\text { Transition, cue-target } \\
\text { congruency, and measure }\end{array}$} & \multicolumn{10}{|c|}{ Stimulus onset asynchrony } \\
\hline & \multicolumn{2}{|c|}{0} & \multicolumn{2}{|c|}{100} & \multicolumn{2}{|c|}{300} & \multicolumn{2}{|c|}{500} & \multicolumn{2}{|c|}{900} \\
\hline & $M$ & $S E$ & $M$ & $S E$ & $M$ & $S E$ & $M$ & $S E$ & $M$ & $S E$ \\
\hline \multicolumn{11}{|c|}{ Cue group: letter23 (continued) } \\
\hline \multicolumn{11}{|l|}{ Task repetition (continued) } \\
\hline \multicolumn{11}{|l|}{ Congruent } \\
\hline RT & 1,122 & 47 & 1,000 & 44 & 885 & 45 & 820 & 37 & 758 & 38 \\
\hline Accuracy & 98.0 & 0.6 & 96.8 & 0.8 & 96.9 & 0.7 & 97.1 & 0.7 & 97.3 & 0.9 \\
\hline \multicolumn{11}{|l|}{ Cue repetition } \\
\hline \multicolumn{11}{|l|}{ Incongruent } \\
\hline RT & 953 & 36 & 827 & 36 & 754 & 34 & 731 & 35 & 714 & 35 \\
\hline Accuracy & 95.9 & 1.0 & 96.0 & 1.1 & 98.4 & 1.0 & 97.5 & 0.9 & 97.5 & 0.7 \\
\hline \multicolumn{11}{|l|}{ Congruent } \\
\hline RT & 905 & 38 & 827 & 33 & 716 & 34 & 719 & 35 & 696 & 30 \\
\hline Accuracy & 97.9 & 0.7 & 98.4 & 0.7 & 98.3 & 0.7 & 95.7 & 1.1 & 98.6 & 0.7 \\
\hline
\end{tabular}

Note. Letter1 = letter cue using initial letter of the words odd, even, high, and low; letter23 = letter cue using second or third letter of the words odd, even, high, and low.

reflecting priming from related cues (Schneider \& Logan, 2005), facilitation from retrieving the same mediator (Logan \& Bundesen, 2004; Logan \& Schneider, in press), or true switch costs (Mayr \& Kliegl, 2003). The difference between the transitions decreased significantly as SOA increased, suggesting that the transition effects reflect processes that occur during the preparation interval, before the target appears. There was no significant difference between the three cue groups and no significant interactions between group and SOA or between group, transition, and SOA, suggesting that the transition and SOA effects were similar in the three groups, albeit for different reasons.

Previous researchers found larger switch costs for arbitrary cues than for word cues (Arbuthnott \& Woodward, 2002; Logan \& Bundesen, 2004; Mayr \& Kliegl, 2000; Miyake et al., 2004). To evaluate this effect, we compared the difference between cue repetitions and task alternations - the traditional measure of switch cost - in the word group (153 ms) with the difference in the letter 1 (215 ms) and letter23 (193 ms) groups. The contrast between the word and letter1 groups was significant, $F(1,114)=19.45, p<$ $.01, M S E=29,577.75$, as was the contrast between the word and the letter23 groups, $F(1,114)=7.83, p<.01, M S E=29,577.75$, replicating previous research.

Overall RT was slower for the letter1 group $(M=942 \mathrm{~ms})$ than for the word group $(M=897 \mathrm{~ms})$ and the letter23 group $(M=895$ $\mathrm{ms}$ ), but none of the pairwise differences were significant. In previous experiments that compared transparent and nontransparent cues, researchers found mixed results. Mayr and Kliegl (2000) found that RT was substantially faster with transparent cues than with nontransparent cues, and Miyake et al. (2004) found a smaller difference in the same direction. Logan and Bundesen (2004) found faster RTs for transparent cues in their first experiment but not in their second experiment. Arbuthnott and Woodward (2002)

Table 2

Analyses of Variance for Mean Reaction Time and Accuracy in Experiment 1

\begin{tabular}{|c|c|c|c|c|c|}
\hline \multirow[b]{2}{*}{ Effect } & \multirow[b]{2}{*}{$d f$} & \multicolumn{2}{|c|}{ Reaction time } & \multicolumn{2}{|c|}{ Accuracy } \\
\hline & & $F$ & MSE & $F$ & $M S E$ \\
\hline Cue group $(\mathrm{G})$ & 2,57 & 0.60 & $722,442.78$ & 0.10 & 232.50 \\
\hline Transition $(\mathrm{T})$ & 2,114 & $183.04 * *$ & $29,577.75$ & $28.98 * *$ & 20.24 \\
\hline Cue-target congruency (C) & 1,57 & $62.75 * *$ & $28,449.16$ & $38.29 * *$ & 43.69 \\
\hline Stimulus onset asynchrony (S) & 4,228 & $453.39 * *$ & $11,363.11$ & $7.16^{* *}$ & 10.21 \\
\hline $\mathrm{G} \times \mathrm{T}$ & 4,114 & 2.23 & $29,577.75$ & 0.95 & 20.24 \\
\hline $\mathrm{G} \times \mathrm{C}$ & 2,57 & $8.46 * *$ & $28,449.16$ & 1.92 & 43.69 \\
\hline $\mathrm{G} \times \mathrm{S}$ & 8,228 & 0.67 & $11,363.11$ & 1.50 & 10.21 \\
\hline $\mathrm{T} \times \mathrm{C}$ & 2,114 & $8.90 * *$ & $8,188.26$ & $7.02 * *$ & 14.69 \\
\hline $\mathrm{T} \times \mathrm{S}$ & 8,456 & $13.09 * *$ & $7,041.77$ & 0.95 & 11.53 \\
\hline $\mathrm{C} \times \mathrm{S}$ & 4,228 & $4.25 * *$ & $5,891.22$ & $7.13 * *$ & 10.76 \\
\hline $\mathrm{G} \times \mathrm{T} \times \mathrm{C}$ & 4,114 & $3.42 *$ & $8,188.26$ & 0.85 & 14.69 \\
\hline $\mathrm{G} \times \mathrm{T} \times \mathrm{S}$ & 16,456 & 1.10 & $7,041.77$ & 0.85 & 11.53 \\
\hline $\mathrm{G} \times \mathrm{C} \times \mathrm{S}$ & 8,228 & 1.97 & $5,891.22$ & $2.16^{*}$ & 10.76 \\
\hline $\mathrm{T} \times \mathrm{C} \times \mathrm{S}$ & 8,456 & 1.09 & $5,429.59$ & 0.86 & 12.15 \\
\hline $\mathrm{G} \times \mathrm{T} \times \mathrm{C} \times \mathrm{S}$ & 16,456 & 1.13 & $5,429.59$ & 1.40 & 12.15 \\
\hline
\end{tabular}

Note. $* p<.05 . * * p<.01$. 
found RTs for transparent cues that were intermediate between RTs for two types of nontransparent cues. However, all of these studies yielded smaller switch costs with transparent cues, which suggests that switch costs are more reliable indicators of processing differences between transparent and nontransparent cues than overall RT.

The most important results for the purposes of this article are the cue-target congruency effects, which are displayed as a function of group and transition in Figure 2. The congruency effects were significant overall and interacted significantly with group. Subjects in the word group showed the same congruency effects as observed by Schneider and Logan (2005). RT was significantly faster for congruent cues and targets $(M=850 \mathrm{~ms})$ than for incongruent cues and targets $(M=943 \mathrm{~ms}), F(1,57)=45.44, p<.01, M S E=$ $28,449.16$, and the congruency effect was greater for task repetitions and task alternations than for cue repetitions (see Figure 2). Subjects in the letter1 group showed very similar congruency effects. RT was significantly faster for congruent cues and targets ( $M=903 \mathrm{~ms})$ than for incongruent cues and targets $(M=982 \mathrm{~ms})$, $F(1,57)=32.62, p<.01, M S E=28,449.16$, suggesting that letter1 subjects used the words odd, even, high, and low as mediators. Subjects in the letter 23 group showed a different pattern of congruency effects. RT was only $18 \mathrm{~ms}$ faster for congruent cues and targets $(M=886 \mathrm{~ms})$ than for incongruent cues and targets $(M=904 \mathrm{~ms})$, and the difference was not significant, $F(1,57)=$ $1.61, p=.21, M S E=28,449.16$, suggesting that subjects used mediators other than the words odd, even, high, and low, or did not use mediators at all.

Analyses of the postexperiment questionnaires confirmed these conclusions about mediator use. In the letter1 group, 17 of the 20 subjects had some knowledge of the correspondence between letters and words: $15 \mathrm{knew}$ the correspondence for all four letters, 1 knew the correspondence for two letters $(O$ and $E)$, and 1 knew the correspondence for one letter $(O)$. In the letter 23 group, 10 subjects had some knowledge of the correspondence between

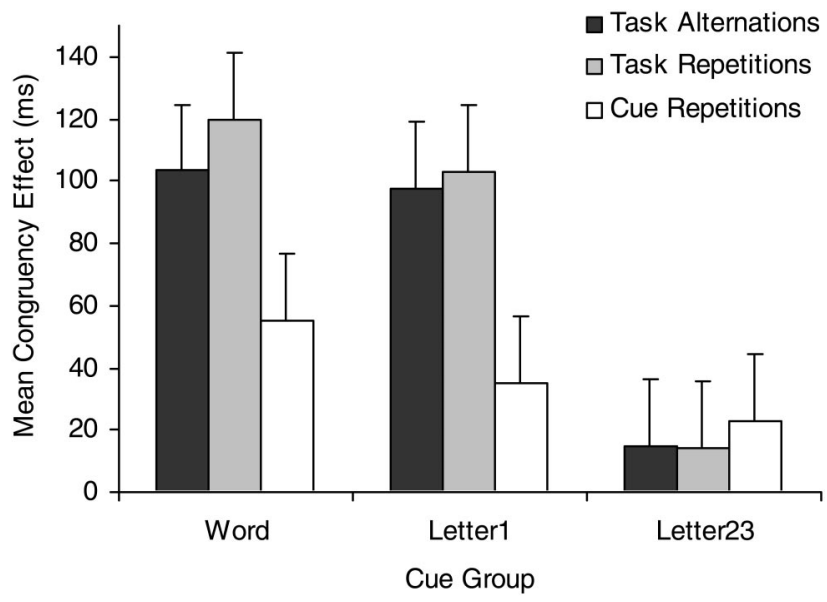

Figure 2. Mean cue-target congruency effect as a function of transition for each cue group in Experiment 1. Error bars represent 95\% confidence intervals based on Fisher's least significant difference for $p<.05$. Letter1 = letter cue using initial letter of the words odd, even, high, and low; letter23 = letter cue using second or third letter of the words odd, even, high, and low. letters and words: only 5 knew the correspondence for all four letters, 4 knew the correspondence for two letters ( $D$ and $V$ ), and 1 knew the correspondence for one letter $(V)$. We cannot determine when subjects discerned the relations between letters and wordssome may have inferred them only when we asked about themand we cannot determine whether the subjects who knew the correspondence used it to translate the letters into word mediators. The RT data provide some insight into individual subjects' use of mediators. In the word group, all subjects knew the (direct) correspondence between cues and words and 19 of 20 showed a positive congruency effect, averaged across transitions and SOA. In the letter1 group, all 20 subjects showed a positive congruency effect. These subjects may have translated letters into word mediators whether or not they could articulate the relations in the postexperiment questionnaire: The congruency effect averaged 81 $\mathrm{ms}$ for the 17 subjects with some knowledge of the relations and 87 $\mathrm{ms}$ for the 3 subjects who expressed no knowledge of the relations. In the letter23 group, subjects who had some knowledge of the relations may have translated letters to word mediators at least some of the time, whereas subjects who had no knowledge did not: 6 of the 10 subjects with some knowledge showed a positive congruency effect, whereas 4 of the 10 subjects with no knowledge showed a positive congruency effect. The mean congruency effect for the 10 subjects with some knowledge was $32 \mathrm{~ms}$; the mean congruency effect for the 10 subjects with no knowledge was -4 $\mathrm{ms}$. However, the difference in congruency effects was not significant, $t(18)=0.99, p=.33$.

\section{Conclusions}

The RT data in all three groups replicated standard findings in the explicit task-cuing procedure: Mean RT and the differences between transitions decreased as SOA increased. Transparent cues produced smaller traditional switch costs (differences between cue repetitions and task alternations) than nontransparent cues. The transparency of cues strongly modulated the effects of congruency between cues and targets. Subjects in the word group, with perfectly transparent cues, showed a 93-ms cue-target congruency effect. Subjects in the letter1 group, who had less transparent cues but nevertheless managed to infer the relation between cues and words, showed a 79-ms cue-target congruency effect, which was comparable in magnitude to that in the word group and suggested that letter1 subjects used words as mediators. Subjects in the letter23 group, who had the least transparent cues, were less likely to infer the relations between cues and words and showed an 18-ms congruency effect, which was not significant and suggested that subjects did not translate letters into word mediators. They must have used other mediators if they used mediators at all.

\section{Experiment 2}

The first experiment showed that subjects who inferred the relations between letter cues and words appeared to use words as mediators. That evidence is essentially correlational. The second experiment was designed to seek evidence for a causal relationship between knowledge of the relations and use of word mediators by testing subjects with nontransparent cues and revealing the relations between cues and words in the middle of the experiment. Subjects were given the second- and third-letter cues, like subjects 
in the letter23 group in Experiment 1, and were tested for knowledge of the cues halfway through the experiment. After this test, they were informed of the relations and given the same cues for the remainder of the experiment. Following Experiment 1, few subjects should infer the relations between these nontransparent cues and the words they correspond to in the first half of the experiment, and so they should not show a strong cue-target congruency effect in the first half of the experiment. However, after being informed of the relations between letters and words, subjects should use the words as mediators, and a strong cue-target congruency effect should be observed in the second half of the experiment.

\section{Method}

Subjects. Twenty individuals from Vanderbilt University completed the experiment in exchange for partial course credit or monetary compensation. None of the subjects had participated in Experiment 1.

Apparatus and stimuli. The apparatus and stimuli were identical to those of Experiment 1, except that only the letter23 cues were used.

Procedure. The procedure was identical to that of Experiment 1, except for one change. Halfway through the experiment (i.e., after six experimental blocks or 480 trials), subjects were asked the three questions about the relationship between the cues and the words, and then they were informed explicitly about the relationship. Subjects then completed the remaining half of the experiment (six experimental blocks or 480 trials). We did not ask about the relations between letters and words at the end of the experiment.

\section{Results and Discussion}

The first trial of each block and trials with RT exceeding 3,000 $\mathrm{ms}(2.6 \%$ of trials) were excluded from all analyses. Trials with incorrect responses (3.2\% of trials) were excluded from the RT analysis. The transition (cue repetition, task repetition, or task alternation) for each trial was determined post hoc based on the relationship between trials $n$ and $n-1$. Cue-target congruency was defined in terms of the relation between the cue and the correct response to the target. Trials were also classified as occurring in the first or second half of the experiment. Mean RT and accuracy were calculated for each combination of half, transition, cue-target congruency, and SOA; these data are provided in Table 3. The RT and accuracy data were submitted to separate 2 (half) $\times 3$ (transition) $\times 2$ (cue-target congruency) $\times 5$ (SOA) repeated measures ANOVAs. Summary tables for these ANOVAs appear in Table 4. Accuracy was high, averaging $97 \%$, and there was no evidence of speed-accuracy trade-offs, so the analyses focus on RTs.

The RT data showed standard effects in the task switching literature. RT decreased significantly as SOA increased; RT was fastest for cue repetitions ( $M=832 \mathrm{~ms})$, intermediate for task repetitions $(M=1,004 \mathrm{~ms})$, and slowest for task alternations $(M=$ $1,099 \mathrm{~ms})$; and the transition effects decreased significantly as SOA increased. RT decreased significantly from the first half of the experiment $(M=1,017 \mathrm{~ms})$ to the second $(M=940 \mathrm{~ms})$, reflecting a practice effect.

As in Experiment 1, the most important results were the congruency effects in the two halves of the experiment. These are plotted as a function of transition in Figure 3. The congruency effect was negligible in the first half of the experiment, before subjects were informed of the relation between cues and words, averaging $22 \mathrm{~ms}, F(1,19)=3.41, p=.08, M S E=21,329.46$. In the questionnaire administered after the first half of the experiment, 12 of 20 subjects had no knowledge of the relations between words and targets. Two subjects knew two relations between letters and words ( 1 knew $V$ and $G$; the other knew $D$ and $V$ ), 1 knew three relations $(D, V$, and $G)$, and 5 knew all four relations. The congruency effect was larger in the 8 subjects who knew some or all of the relations $(M=69 \mathrm{~ms})$ than in the 12 subjects who knew none of the relations $(M=-8 \mathrm{~ms})$; the difference in congruency effects was marginally significant, $t(18)=2.07, p=$ .053. Seven of the 8 subjects who knew the relations showed positive congruency effects; 5 of the 12 subjects who did not know the relations showed positive congruency effects. By contrast, the congruency effect was substantial in the second half of the experiment, after subjects were informed, averaging $68 \mathrm{~ms}, F(1,19)=$ $32.05, p<.01, M S E=21,329.46$. Nineteen of the 20 subjects showed positive congruency effects after being informed of the relations. All 12 of the subjects who did not know the relations in the first half of the experiment showed positive congruency effects in the second half after being informed of the relations.

\section{Conclusions}

This experiment examined congruency effects before and after subjects were informed of the relations between nontransparent letter cues and the corresponding words. The congruency effects were negligible before subjects were informed and substantial afterward, suggesting that subjects used the words as mediators after they became aware of the relations between letters and words. The effect of the instructional manipulation goes beyond the correlational evidence in Experiment 1 and suggests a causal relationship between knowledge of cue-word relations and the use of the words as mediators.

\section{Experiment 3}

The use of a mediator adds another step to the process of interpreting an instructional cue. Subjects must encode the cue, retrieve the mediator, and then use the mediator to retrieve the task set or goal to enable performance. It would be more efficient to bypass mediator retrieval and use the cue to retrieve the task set or goal. However, the arbitrary relation between nontransparent cues and task names or response categories makes the extra step necessary, at least early in practice. With practice, subjects may learn to associate arbitrary cues and targets directly with appropriate responses and bypass mediator retrieval, saving a step and speeding RT (Arrington \& Logan, 2004b). The third experiment was designed to investigate the effects of practice on mediator retrieval, to determine whether subjects can learn to abandon mediator retrieval and use direct associations between nontransparent cues and task sets or goals to enable performance. Subjects were trained on the letter1 cues from Experiment $1(O, E, H$, and $L)$ for 10 sessions. Following Experiment 1, we expected strong cue-target congruency effects in the early sessions. However, as practice progressed, we expected mediator retrieval to drop out and the cue-target congruency effects to diminish and disappear.

\section{Method}

Subjects. Eight individuals from Vanderbilt University each completed 10 sessions of the experiment in exchange for monetary compensation. None of the subjects had participated in Experiments 1 or 2. 
Table 3

Mean Reaction Time (RT; in Milliseconds) and Accuracy Across Subjects at Each Stimulus Onset Asynchrony (in Milliseconds) as a Function of Half, Transition, and Cue-Target Congruency in Experiment 2

\begin{tabular}{|c|c|c|c|c|c|c|c|c|c|c|}
\hline \multirow{3}{*}{$\begin{array}{l}\text { Transition, cue-target } \\
\text { congruency, and measure }\end{array}$} & \multicolumn{10}{|c|}{ Stimulus onset asynchrony } \\
\hline & \multicolumn{2}{|c|}{0} & \multicolumn{2}{|c|}{100} & \multicolumn{2}{|c|}{300} & \multicolumn{2}{|c|}{500} & \multicolumn{2}{|c|}{900} \\
\hline & $M$ & $S E$ & $M$ & $S E$ & $M$ & $S E$ & $M$ & $S E$ & $M$ & $S E$ \\
\hline \multicolumn{11}{|c|}{ First half } \\
\hline \multicolumn{11}{|l|}{ Task alternation } \\
\hline RT & 1,368 & 56 & 1,269 & 60 & 1,165 & 68 & 989 & 47 & 950 & 47 \\
\hline Accuracy & 96.3 & 1.1 & 95.6 & 1.2 & 96.2 & 0.8 & 96.4 & 1.2 & 97.9 & 0.7 \\
\hline \multicolumn{11}{|l|}{ Congruent } \\
\hline $\mathrm{RT}$ & 1,344 & 55 & 1,234 & 59 & 1,109 & 60 & 996 & 47 & 904 & 49 \\
\hline Accuracy & 95.7 & 1.2 & 96.7 & 0.8 & 96.4 & 1.0 & 96.7 & 0.9 & 97.1 & 0.9 \\
\hline \multicolumn{11}{|l|}{ Task repetition } \\
\hline \multicolumn{11}{|l|}{ Incongruent } \\
\hline RT & 1,250 & 64 & 1,130 & 64 & 1,065 & 56 & 1,002 & 61 & 912 & 55 \\
\hline Accuracy & 96.4 & 1.0 & 98.4 & 0.8 & 97.2 & 1.2 & 99.3 & 0.5 & 98.3 & 1.0 \\
\hline \multicolumn{11}{|l|}{ Congruent } \\
\hline RT & 1,207 & 64 & 1,154 & 66 & 999 & 61 & 905 & 40 & 872 & 46 \\
\hline Accuracy & 98.3 & 1.2 & 100.0 & 0 & 98.1 & 0.8 & 97.7 & 1.0 & 97.9 & 0.8 \\
\hline \multicolumn{11}{|l|}{ Cue repetition } \\
\hline \multicolumn{11}{|l|}{ Incongruent } \\
\hline $\mathrm{RT}$ & 1,006 & 47 & 944 & 36 & 825 & 41 & 765 & 34 & 775 & 33 \\
\hline Accuracy & 97.3 & 1.4 & 97.9 & 1.0 & 98.3 & 1.0 & 96.8 & 1.1 & 97.5 & 1.1 \\
\hline \multicolumn{11}{|l|}{ Congruent } \\
\hline RT & 1,057 & 53 & 957 & 42 & 840 & 48 & 733 & 27 & 772 & 37 \\
\hline Accuracy & 97.0 & 1.3 & 98.8 & 0.9 & 97.4 & 0.9 & 97.6 & 1.0 & 97.5 & 1.0 \\
\hline \multicolumn{11}{|c|}{ Second half } \\
\hline \multicolumn{11}{|l|}{ Task alternation } \\
\hline \multicolumn{11}{|l|}{ Incongruent } \\
\hline $\mathrm{RT}$ & 1,303 & 51 & 1,226 & 55 & 1,091 & 58 & 1,041 & 56 & 936 & 41 \\
\hline Accuracy & 93.6 & 1.5 & 92.6 & 1.6 & 94.1 & 1.4 & 95.3 & 1.5 & 95.3 & 1.0 \\
\hline \multicolumn{11}{|l|}{ Congruent } \\
\hline $\mathrm{RT}$ & 1,198 & 45 & 1,146 & 55 & 983 & 48 & 902 & 43 & 824 & 43 \\
\hline Accuracy & 95.1 & 1.4 & 96.2 & 1.2 & 97.8 & 0.7 & 97.4 & 0.7 & 94.4 & 1.5 \\
\hline Task repetition & & & & & & & & & & \\
\hline Incongruent & & & & & & & & & & \\
\hline RT & 1,160 & 55 & 1,113 & 63 & 969 & 43 & 931 & 50 & 802 & 35 \\
\hline Accuracy & 93.4 & 1.7 & 93.8 & 1.7 & 93.9 & 2.3 & 96.0 & 1.7 & 95.7 & 1.5 \\
\hline Congruent & & & & & & & & & & \\
\hline $\mathrm{RT}$ & 1,100 & 58 & 986 & 57 & 910 & 44 & 832 & 34 & 779 & 36 \\
\hline Accuracy & 98.1 & 0.9 & 98.9 & 0.7 & 99.5 & 0.5 & 98.1 & 0.9 & 97.4 & 1.2 \\
\hline Cue repetition & & & & & & & & & & \\
\hline Incongruent & & & & & & & & & & \\
\hline $\mathrm{RT}$ & 937 & 36 & 885 & 51 & 791 & 32 & 746 & 31 & 676 & 35 \\
\hline Accuracy & 96.2 & 1.3 & 97.3 & 1.3 & 97.8 & 0.9 & 97.9 & 1.2 & 97.0 & 1.5 \\
\hline Congruent & & & & & & & & & & \\
\hline RT & 948 & 40 & 877 & 39 & 735 & 35 & 697 & 30 & 677 & 24 \\
\hline Accuracy & 96.4 & 1.2 & 95.6 & 1.7 & 97.8 & 0.9 & 96.6 & 1.4 & 97.9 & 0.9 \\
\hline
\end{tabular}

Apparatus and stimuli. The apparatus and stimuli were identical to those of Experiments 1 and 2, except that only the letter1 cues were used.

Procedure. The procedure was identical to the letter1 condition in Experiment 1, except that the three questions at the end of the experiment were omitted and each subject completed 10 sessions (for a total of 9,600 experimental trials). Subjects completed 1 or 2 sessions (e.g., morning and afternoon) each day.

\section{Results and Discussion}

The first trial of each block and trials with RT exceeding 3,000 $\mathrm{ms}(0.5 \%$ of trials $)$ were excluded from all analyses. Trials with incorrect responses $(3.1 \%$ of trials) were excluded from the RT analysis. The transition (cue repetition, task repetition, or task alternation) for each trial was determined post hoc based on the relation between trials $n$ and $n-1$. Cue-target congruency was determined post hoc based on the relation between the cue and the correct response to the target. Mean RT and accuracy were calculated for each combination of session, transition, cue-target congruency, and SOA; these data are provided in Table 5. The RT and accuracy data were submitted to separate 10 (session) $\times 3$ (transition) $\times 2$ (cue-target congruency) $\times 5(\mathrm{SOA})$ repeated measures ANOVAs. The summary tables for these ANOVAs are presented 
Table 4

Analyses of Variance for Mean Reaction Time and Accuracy in Experiment 2

\begin{tabular}{|c|c|c|c|c|c|}
\hline \multirow[b]{2}{*}{ Effect } & \multirow[b]{2}{*}{$d f$} & \multicolumn{2}{|c|}{ Reaction time } & \multicolumn{2}{|c|}{ Accuracy } \\
\hline & & $F$ & $M S E$ & $F$ & $M S E$ \\
\hline Half $(\mathrm{H})$ & 1,19 & $9.82 * *$ & $179,594.05$ & $7.96^{*}$ & 53.19 \\
\hline Transition (T) & 2,38 & $79.83^{* *} *$ & $91,734.05$ & $8.73 * *$ & 33.58 \\
\hline Cue-target congruency (C) & 1,19 & $9.36^{* *}$ & $64,251.16$ & $7.41^{*}$ & 41.40 \\
\hline Stimulus onset asynchrony (S) & 4,76 & $112.98 * *$ & $40,328.61$ & 1.85 & 20.86 \\
\hline $\mathrm{H} \times \mathrm{T}$ & 2,38 & 0.44 & $37,958.32$ & 1.24 & 25.54 \\
\hline $\mathrm{H} \times \mathrm{C}$ & 1,19 & $7.25^{*}$ & $21,329.46$ & $8.51 * *$ & 23.18 \\
\hline $\mathrm{H} \times \mathrm{S}$ & 4,76 & 1.99 & $14,412.29$ & 1.96 & 14.70 \\
\hline $\mathrm{T} \times \mathrm{C}$ & 2,38 & $7.44 * *$ & $15,771.41$ & $5.58 * *$ & 24.18 \\
\hline $\mathrm{T} \times \mathrm{S}$ & 8,152 & $3.78 * *$ & $17,648.60$ & 0.42 & 25.28 \\
\hline $\mathrm{C} \times \mathrm{S}$ & 4,76 & 1.26 & $12,603.64$ & 1.59 & 21.43 \\
\hline $\mathrm{H} \times \mathrm{T} \times \mathrm{C}$ & 2,38 & 2.08 & $9,548.59$ & $3.93 *$ & 24.02 \\
\hline $\mathrm{H} \times \mathrm{T} \times \mathrm{S}$ & 8,152 & 0.46 & $15,184.25$ & 0.38 & 20.00 \\
\hline $\mathrm{H} \times \mathrm{C} \times \mathrm{S}$ & 4,76 & 0.63 & $10,545.17$ & 0.43 & 25.60 \\
\hline $\mathrm{T} \times \mathrm{C} \times \mathrm{S}$ & 8,152 & 0.44 & $13,999.04$ & 1.32 & 19.15 \\
\hline $\mathrm{H} \times \mathrm{T} \times \mathrm{C} \times \mathrm{S}$ & 8,152 & 1.22 & $12,195.36$ & 0.35 & 25.27 \\
\hline
\end{tabular}

Note. $* p<.05 . \quad * * p<.01$.

in Table 6. As in the previous experiments, accuracy was high $(M=97 \%)$ and there was no evidence of speed-accuracy tradeoffs, so the analyses focused on RT.

Performance in the 1st session was much like the performance of the letter1 group in Experiment 1. There were strong effects of SOA, transition, and cue-target congruency. RT decreased from $1,049 \mathrm{~ms}$ at $\mathrm{SOA}=0 \mathrm{~ms}$ to $716 \mathrm{~ms}$ at $\mathrm{SOA}=900 \mathrm{~ms}$. Cue repetitions $(M=768 \mathrm{~ms})$ were faster than task repetitions $(M=$ $905 \mathrm{~ms})$, which were faster than task alternations $(M=952 \mathrm{~ms})$. RTs to congruent cue-target combinations were $82 \mathrm{~ms}$ faster than RTs to incongruent cue-target combinations. Performance changed relatively smoothly between Sessions 1 and 10 (see Table 5). Cue repetition benefits (task repetition RT minus cue repetition RT) and true switch costs (task alternation RT minus task repetition RT) are plotted as a function of session in Figure 4; the

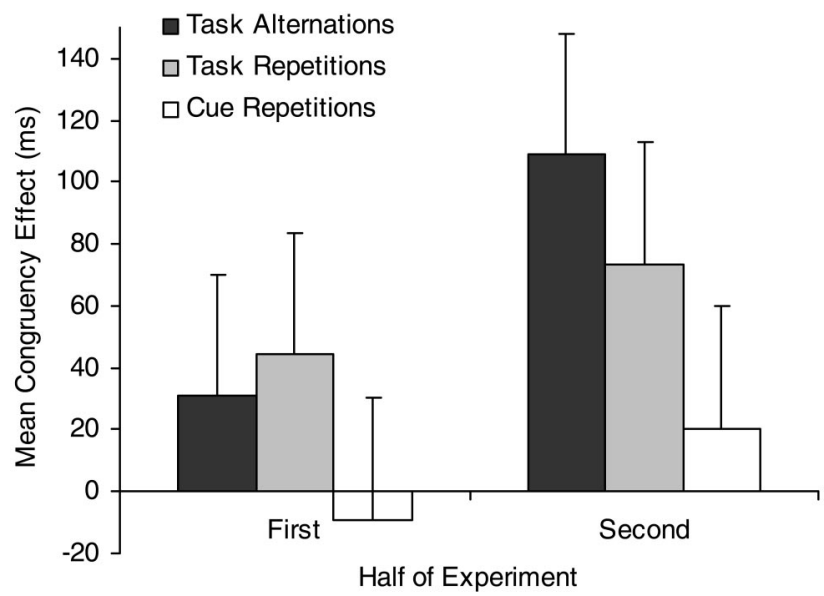

Figure 3. Mean cue-target congruency effect as a function of transition for each half of Experiment 2. Error bars represent 95\% confidence intervals based on Fisher's least significant difference for $p<.05$. congruency effect for each transition is plotted as a function of session in Figure 5.

By the 10th session, performance had changed dramatically. The effects of SOA, transition, and congruency were all diminished. RT was $649 \mathrm{~ms}$ at $\mathrm{SOA}=0 \mathrm{~ms}$ and $528 \mathrm{~ms}$ at $\mathrm{SOA}=900$ ms. Practice effects were greater for the shorter SOAs, perhaps because there was more room for improvement. RT was $554 \mathrm{~ms}$ for cue repetitions, $572 \mathrm{~ms}$ for task repetitions, and $597 \mathrm{~ms}$ for task alternations. The difference between cue repetitions and task repetitions was not significant, $F(1,126)=2.91, p<.10, M S E=$ $4,662.81$, but the difference between task repetitions and task alternations was significant, $F(1,126)=5.15, p<.05, M S E=$ 4,662.81. The congruency effect shrunk to $20 \mathrm{~ms}$ but remained significant, $F(1,63)=8.18, p<.01, M S E=2,933.85$. Perhaps further practice would eliminate it entirely.

These impressive changes with practice suggest there was a transition from semantic memory retrieval early in practice to episodic memory retrieval later in practice (Arrington \& Logan, 2004b; Logan, 1988). Early in practice, subjects encoded the cue, retrieved the mediator associated with it, and used the mediator to retrieve a task set or goal. Over practice, subjects came to associate specific cues and specific targets with specific responses and stored these associations in episodic memory. When specific combinations of cues and targets repeated, the associated response could be retrieved directly from episodic memory, bypassing mediator retrieval. Repeated practice strengthened the associations, adding instance after instance to episodic memory (Logan, 1988). As a result, RT became faster overall and the cue-target congruency effect, identified with mediator retrieval, diminished.

This transition to episodic memory retrieval also explains the reduction in the transition effects with practice. Logan and Bundesen (2003) and Schneider and Logan (2005) explained transition effects in terms of cue encoding, instantiated as a race between semantic memory and traces of the last cue in short-term memory. Cue repetitions match short-term memory as well as (text continues on page 359) 
Table 5

Mean Reaction Time (RT; in Milliseconds) and Accuracy Across Subjects at Each Stimulus Onset Asynchrony (in Milliseconds) as a Function of Session, Transition, and Cue-Target Congruency in Experiment 3

\begin{tabular}{|c|c|c|c|c|c|c|c|c|c|c|}
\hline \multirow{3}{*}{$\begin{array}{l}\text { Transition, cue-target } \\
\text { congruency, and measure }\end{array}$} & \multicolumn{10}{|c|}{ Stimulus onset asynchrony } \\
\hline & \multicolumn{2}{|c|}{0} & \multicolumn{2}{|c|}{100} & \multicolumn{2}{|c|}{300} & \multicolumn{2}{|c|}{500} & \multicolumn{2}{|c|}{900} \\
\hline & $M$ & $S E$ & $M$ & $S E$ & $M$ & $S E$ & $M$ & $S E$ & $M$ & $S E$ \\
\hline \multicolumn{11}{|c|}{ Session 1} \\
\hline \multicolumn{11}{|l|}{ Task alternation } \\
\hline \multicolumn{11}{|l|}{ Incongruent } \\
\hline $\mathrm{RT}$ & 1,270 & 94 & 1,135 & 79 & 1,003 & 95 & 866 & 102 & 772 & 74 \\
\hline Accuracy & 93.2 & 2.7 & 94.6 & 2.5 & 93.7 & 2.8 & 92.8 & 2.7 & 96.7 & 1.7 \\
\hline \multicolumn{11}{|l|}{ Congruent } \\
\hline RT & 1,080 & 59 & 996 & 86 & 878 & 96 & 794 & 82 & 724 & 88 \\
\hline Accuracy & 96.6 & 1.7 & 97.2 & 1.3 & 98.2 & 1.2 & 97.3 & 1.1 & 97.2 & 1.5 \\
\hline \multicolumn{11}{|l|}{ Task repetition } \\
\hline \multicolumn{11}{|l|}{ Incongruent } \\
\hline $\mathrm{RT}$ & 1,137 & 88 & 1,072 & 85 & 927 & 81 & 891 & 71 & 741 & 74 \\
\hline Accuracy & 94.2 & 2.0 & 94.8 & 2.1 & 96.0 & 1.0 & 96.0 & 2.0 & 95.4 & 1.8 \\
\hline \multicolumn{11}{|l|}{ Congruent } \\
\hline RT & 989 & 69 & 940 & 96 & 818 & 93 & 797 & 93 & 739 & 98 \\
\hline Accuracy & 98.1 & 1.4 & 99.6 & .4 & 100.0 & 0 & 97.9 & 1.1 & 98.3 & .9 \\
\hline \multicolumn{11}{|l|}{ Cue repetition } \\
\hline \multicolumn{11}{|l|}{ Incongruent } \\
\hline RT & 951 & 66 & 852 & 63 & 708 & 58 & 733 & 65 & 678 & 61 \\
\hline Accuracy & 98.5 & .7 & 97.1 & 1.6 & 96.4 & 1.4 & 97.6 & .9 & 96.7 & 1.4 \\
\hline \multicolumn{11}{|l|}{ Congruent } \\
\hline RT & 867 & 62 & 855 & 60 & 707 & 58 & 684 & 59 & 643 & 67 \\
\hline Accuracy & 99.6 & .4 & 99.5 & .5 & 99.0 & .6 & 96.7 & .8 & 96.9 & 1.5 \\
\hline
\end{tabular}

Session 2

Task alternation

Incongruent

RT

Accuracy

Congruent

RT

Accuracy

Task repetition Incongruent

RT

Accuracy

Congruent

RT

Accuracy

Cue repetition

Incongruent

RT

Accuracy

Congruent

RT

Accuracy

$\begin{array}{cccccccccc}993 & 74 & 877 & 64 & 749 & 70 & 693 & 78 & 667 & 70 \\ 95.3 & 1.9 & 93.3 & 2.9 & 93.1 & 3.3 & 93.9 & 3.3 & 93.6 & 2.7 \\ & & & & & & & & & \\ 861 & 62 & 780 & 59 & 676 & 72 & 635 & 65 & 606 & 77 \\ 97.7 & 1.1 & 98.1 & .9 & 97.9 & .8 & 97.8 & .7 & 95.9 & 1.7\end{array}$

$\begin{array}{llllllllll}931 & 55 & 883 & 59 & 705 & 61 & 698 & 78 & 653 & 80\end{array}$

$\begin{array}{rrrrrrrrr}95.7 & 1.8 & 93.3 & 4.2 & 96.8 & 2.5 & 95.5 & 2.1 & 94.4\end{array}$

$\begin{array}{lllllllllll}804 & 54 & 737 & 60 & 658 & 78 & 615 & 60 & 601 & 75\end{array}$

$\begin{array}{lrrrrrrrr}100.0 & 0 & 99.1 & .6 & 98.6 & .7 & 96.9 & 1.2 & 99.5\end{array}$

$\begin{array}{llllllllll}742 & 44 & 706 & 28 & 658 & 61 & 631 & 52 & 562 & 40\end{array}$

$\begin{array}{rrrrrrrrrr}96.5 & 1.9 & 98.6 & .7 & 96.7 & 2.2 & 96.9 & 1.5 & 96.6 & 1.2\end{array}$

$\begin{array}{llllllllll}774 & 62 & 662 & 47 & 604 & 51 & 584 & 54 & 589 & 66\end{array}$

$\begin{array}{llllllllll}97.8 & 1.1 & 96.0 & 2.3 & 97.2 & .9 & 97.9 & .8 & 95.4 & 1.9\end{array}$

Session 3

Task alternation Incongruent

RT

Accuracy

Congruent

RT

Accuracy

Task repetition

Incongruent

RT

Accuracy

$\begin{array}{cccccccccc}878 & 57 & 800 & 65 & 693 & 78 & 703 & 76 & 620 & 74 \\ 96.6 & 1.2 & 92.8 & 3.5 & 95.2 & 2.0 & 96.1 & 2.2 & 97.0 & 1.6 \\ 821 & 55 & 736 & 50 & 657 & 81 & 629 & 89 & 584 & 62 \\ 98.3 & .6 & 97.1 & 1.1 & 97.4 & 1.3 & 98.5 & .5 & 95.4 & 1.6 \\ & & & & & & & & & \\ 848 & 46 & 759 & 58 & 693 & 76 & 627 & 74 & 606 & 66 \\ 95.0 & 2.8 & 95.5 & 3.2 & 95.6 & 2.3 & 96.3 & 3.8 & 97.7 & 1.9\end{array}$


Table 5 (continued)

\begin{tabular}{|c|c|c|c|c|c|c|c|c|c|c|}
\hline \multirow{3}{*}{$\begin{array}{l}\text { Transition, cue-target } \\
\text { congruency, and measure }\end{array}$} & \multicolumn{10}{|c|}{ Stimulus onset asynchrony } \\
\hline & \multicolumn{2}{|c|}{0} & \multicolumn{2}{|c|}{100} & \multicolumn{2}{|c|}{300} & \multicolumn{2}{|c|}{500} & \multicolumn{2}{|c|}{900} \\
\hline & $M$ & $S E$ & $M$ & $S E$ & $M$ & $S E$ & $M$ & $S E$ & $M$ & $S E$ \\
\hline \multicolumn{11}{|c|}{ Session 3 (continued) } \\
\hline \multicolumn{11}{|l|}{ Task repetition (continued) } \\
\hline \multicolumn{11}{|l|}{ Congruent } \\
\hline RT & 756 & 62 & 692 & 60 & 643 & 80 & 620 & 81 & 593 & 76 \\
\hline Accuracy & 99.0 & 1.0 & 99.4 & .6 & 98.5 & 1.1 & 99.5 & .5 & 97.7 & .9 \\
\hline \multicolumn{11}{|l|}{ Cue repetition } \\
\hline \multicolumn{11}{|l|}{ Incongruent } \\
\hline $\mathrm{RT}$ & 745 & 51 & 647 & 47 & 606 & 64 & 619 & 58 & 573 & 60 \\
\hline Accuracy & 98.6 & 1.0 & 96.9 & 1.3 & 98.3 & 1.2 & 96.9 & 2.5 & 98.1 & 1.0 \\
\hline \multicolumn{11}{|l|}{ Congruent } \\
\hline RT & 725 & 48 & 653 & 60 & 682 & 77 & 598 & 48 & 555 & 54 \\
\hline Accuracy & 98.3 & 1.7 & 98.6 & 1.4 & 98.9 & .8 & 97.8 & 1.2 & 96.5 & 1.8 \\
\hline \multicolumn{11}{|c|}{ Session 4} \\
\hline Task alternation & & & & & & & & & & \\
\hline Incongruent & & & & & & & & & & \\
\hline RT & 843 & 58 & 774 & 70 & 658 & 62 & 631 & 70 & 606 & 81 \\
\hline Accuracy & 96.5 & 1.4 & 94.5 & 2.4 & 94.0 & 3.3 & 96.3 & 2.8 & 95.1 & 2.4 \\
\hline Congruent & & & & & & & & & & \\
\hline RT & 787 & 61 & 698 & 67 & 614 & 80 & 583 & 87 & 554 & 78 \\
\hline Accuracy & 97.7 & .6 & 97.6 & .9 & 97.6 & .5 & 96.6 & 2.3 & 96.9 & 1.3 \\
\hline Task repetition & & & & & & & & & & \\
\hline Incongruent & & & & & & & & & & \\
\hline RT & 805 & 68 & 741 & 90 & 679 & 96 & 607 & 85 & 556 & 55 \\
\hline Accuracy & 94.8 & 3.8 & 98.2 & 1.3 & 95.0 & 2.7 & 98.5 & 1.0 & 97.2 & 2.0 \\
\hline Congruent & & & & & & & & & & \\
\hline $\mathrm{RT}$ & 718 & 62 & 645 & 58 & 611 & 81 & 541 & 72 & 525 & 67 \\
\hline Accuracy & 100.0 & 0 & 100.0 & 0 & 98.5 & .7 & 97.5 & 1.3 & 97.6 & 1.9 \\
\hline Cue repetition & & & & & & & & & & \\
\hline Incongruent & & & & & & & & & & \\
\hline $\mathrm{RT}$ & 714 & 53 & 672 & 61 & 583 & 46 & 549 & 55 & 544 & 53 \\
\hline Accuracy & 98.5 & 1.0 & 98.9 & .7 & 94.7 & 2.9 & 96.8 & 1.8 & 95.8 & 2.7 \\
\hline Congruent & & & & & & & & & & \\
\hline $\mathrm{RT}$ & 695 & 68 & 592 & 49 & 583 & 57 & 534 & 56 & 546 & 68 \\
\hline Accuracy & 98.3 & .8 & 96.9 & 1.0 & 100.0 & 0 & 97.4 & 2.0 & 95.4 & $2.3 \backslash$ \\
\hline & & & & Session & & & & & & \\
\hline Task alternation & & & & & & & & & & \\
\hline Incongruent & & & & & & & & & & \\
\hline $\mathrm{RT}$ & 830 & 61 & 756 & 53 & 661 & 59 & 655 & 78 & 601 & 66 \\
\hline Accuracy & 94.2 & 2.4 & 96.3 & 1.7 & 96.8 & 1.4 & 96.3 & 1.4 & 97.0 & 1.2 \\
\hline Congruent & & & & & & & & & & \\
\hline $\mathrm{RT}$ & 780 & 53 & 697 & 50 & 620 & 60 & 574 & 52 & 583 & 62 \\
\hline Accuracy & 97.2 & .3 & 97.9 & .8 & 98.4 & .7 & 99.0 & .5 & 99.2 & .4 \\
\hline Task repetition & & & & & & & & & & \\
\hline Incongruent & & & & & & & & & & \\
\hline RT & 781 & 45 & 710 & 52 & 684 & 88 & 634 & 69 & 578 & 47 \\
\hline Accuracy & 97.6 & 1.2 & 99.1 & .6 & 95.5 & 3.9 & 99.1 & .6 & 97.0 & 1.9 \\
\hline Congruent & & & & & & & & & & \\
\hline RT & 722 & 53 & 661 & 57 & 572 & 51 & 586 & 73 & 527 & 55 \\
\hline Accuracy & 98.9 & .7 & 98.5 & .7 & 98.4 & .8 & 97.6 & 1.2 & 99.4 & .6 \\
\hline Cue repetition & & & & & & & & & & \\
\hline Incongruent & & & & & & & & & & \\
\hline $\mathrm{RT}$ & 720 & 42 & 658 & 49 & 617 & 68 & 570 & 46 & 523 & 38 \\
\hline Accuracy & 98.8 & 1.2 & 96.5 & 1.7 & 96.3 & 2.1 & 95.3 & 2.0 & 95.6 & 2.0 \\
\hline Congruent & & & & & & & & & & \\
\hline $\mathrm{RT}$ & 701 & 58 & 610 & 31 & 584 & 48 & 595 & 73 & 559 & 68 \\
\hline Accuracy & 99.1 & .6 & 96.9 & 1.2 & 98.5 & .8 & 97.4 & 1.6 & 97.6 & 1.6 \\
\hline
\end{tabular}


Table 5 (continued)

\begin{tabular}{|c|c|c|c|c|c|c|c|c|c|c|}
\hline \multirow{3}{*}{$\begin{array}{l}\text { Transition, cue-target } \\
\text { congruency, and measure }\end{array}$} & \multicolumn{10}{|c|}{ Stimulus onset asynchrony } \\
\hline & \multicolumn{2}{|c|}{0} & \multicolumn{2}{|c|}{100} & \multicolumn{2}{|c|}{300} & \multicolumn{2}{|c|}{500} & \multicolumn{2}{|c|}{900} \\
\hline & $M$ & $S E$ & $M$ & $S E$ & $M$ & $S E$ & $M$ & $S E$ & $M$ & $S E$ \\
\hline \multicolumn{11}{|c|}{ Session 6} \\
\hline \multicolumn{11}{|l|}{ Task alternation } \\
\hline $\mathrm{RT}$ & 754 & 43 & 703 & 53 & 617 & 41 & 592 & 45 & 584 & 63 \\
\hline Accuracy & 96.2 & 1.5 & 95.6 & 1.3 & 96.2 & 1.9 & 97.3 & 1.2 & 99.0 & .8 \\
\hline \multicolumn{11}{|l|}{ Congruent } \\
\hline RT & 724 & 43 & 638 & 44 & 575 & 49 & 550 & 63 & 534 & 61 \\
\hline Accuracy & 98.1 & .9 & 97.8 & .9 & 98.9 & .6 & 97.6 & 1.2 & 98.0 & 1.2 \\
\hline \multicolumn{11}{|l|}{ Task repetition } \\
\hline \multicolumn{11}{|l|}{ Incongruent } \\
\hline RT & 694 & 44 & 683 & 62 & 614 & 53 & 595 & 71 & 554 & 70 \\
\hline Accuracy & 96.6 & 2.0 & 96.8 & 2.6 & 97.5 & 1.8 & 96.3 & 1.5 & 96.3 & 2.3 \\
\hline \multicolumn{11}{|l|}{ Congruent } \\
\hline RT & 669 & 42 & 604 & 47 & 545 & 47 & 538 & 60 & 514 & 57 \\
\hline Accuracy & 97.6 & 1.4 & 99.4 & .6 & 97.6 & .9 & 97.3 & 1.9 & 98.2 & .9 \\
\hline \multicolumn{11}{|l|}{ Cue repetition } \\
\hline \multicolumn{11}{|l|}{ Incongruent } \\
\hline RT & 671 & 43 & 655 & 75 & 571 & 52 & 551 & 52 & 539 & 53 \\
\hline Accuracy & 99.6 & .4 & 98.2 & 1.9 & 98.8 & 1.2 & 96.7 & 1.7 & 97.7 & 1.2 \\
\hline \multicolumn{11}{|l|}{ Congruent } \\
\hline RT & 667 & 48 & 574 & 36 & 576 & 55 & 523 & 47 & 516 & 43 \\
\hline Accuracy & 98.7 & .9 & 98.8 & .8 & 97.2 & 1.2 & 96.7 & 1.0 & 96.7 & 1.5 \\
\hline
\end{tabular}

Session 7

Task alternation

Incongruent

RT

Accuracy

Congruent

RT

Accuracy

Task repetition

Incongruent

RT

Accuracy

Congruent

RT

Accuracy

Cue repetition

Incongruent

RT

Accuracy

Congruent

RT

Accuracy

\begin{tabular}{|c|c|c|c|c|c|c|c|c|c|}
\hline 764 & 68 & 677 & 58 & 630 & 60 & 576 & 51 & 574 & 76 \\
\hline 95.3 & 1.8 & 96.4 & 1.5 & 93.7 & 2.3 & 94.3 & 2.6 & 96.2 & 2.3 \\
\hline 721 & 61 & 639 & 56 & 572 & 51 & 565 & 65 & 562 & 87 \\
\hline 96.6 & 1.1 & 96.2 & .9 & 96.4 & .7 & 96.4 & 1.3 & 97.1 & 1.7 \\
\hline 723 & 61 & 626 & 53 & 599 & 62 & 587 & 72 & 556 & 55 \\
\hline 94.8 & 3.4 & 97.8 & 1.5 & 98.1 & 1.4 & 95.0 & 3.1 & 95.9 & 2.8 \\
\hline 649 & 43 & 599 & 60 & 546 & 51 & 527 & 47 & 511 & 60 \\
\hline 97.8 & .9 & 97.1 & .9 & 100.0 & 0 & 98.9 & .7 & 100.0 & 0 \\
\hline 655 & 51 & 572 & 34 & 553 & 57 & 542 & 47 & 565 & 79 \\
\hline 96.0 & 2.1 & 97.6 & .9 & 96.5 & 1.6 & 94.1 & 1.8 & 97.2 & 1.5 \\
\hline 625 & 42 & 584 & 44 & 562 & 63 & 526 & 46 & 527 & 67 \\
\hline 96.2 & 1.4 & 97.4 & .8 & 97.6 & 1.3 & 96.0 & 2.2 & 95.8 & 4 \\
\hline
\end{tabular}

Session 8

Task alternation

Incongruent

RT

Accuracy

Congruent

RT

Accuracy

Task repetition

Incongruent

RT

Accuracy

Congruent

RT

Accuracy

$\begin{array}{cccccccccc}749 & 66 & 657 & 51 & 628 & 68 & 587 & 71 & 544 & 55 \\ 94.2 & 1.7 & 95.7 & 1.5 & 94.1 & 2.4 & 95.1 & 2.2 & 95.2 & 2.5 \\ 679 & 46 & 624 & 51 & 572 & 62 & 537 & 58 & 528 & 68 \\ 95.7 & 1.5 & 96.2 & 1.2 & 95.5 & 1.4 & 94.5 & 2.1 & 96.7 & 1.3 \\ & & & & & & & & & \\ \\ 667 & 47 & 619 & 44 & 575 & 60 & 581 & 62 & 541 & 68 \\ 95.2 & 3.0 & 99.6 & .4 & 97.3 & 2.7 & 97.2 & 2.8 & 96.1 & 2.2 \\ 647 & 43 & 583 & 35 & 537 & 47 & 517 & 59 & 492 & 58 \\ 96.3 & 1.7 & 97.8 & 1.2 & 97.7 & 1.3 & 97.7 & 1.2 & 98.0 & .8\end{array}$


Table 5 (continued)

\begin{tabular}{|c|c|c|c|c|c|c|c|c|c|c|}
\hline \multirow{3}{*}{$\begin{array}{l}\text { Transition, cue-target } \\
\text { congruency, and measure }\end{array}$} & \multicolumn{10}{|c|}{ Stimulus onset asynchrony } \\
\hline & \multicolumn{2}{|c|}{0} & \multicolumn{2}{|c|}{100} & \multicolumn{2}{|c|}{300} & \multicolumn{2}{|c|}{500} & \multicolumn{2}{|c|}{900} \\
\hline & $M$ & $S E$ & $M$ & $S E$ & $M$ & $S E$ & $M$ & $S E$ & $M$ & $S E$ \\
\hline \multicolumn{11}{|c|}{ Session 8 (continued) } \\
\hline Cue repetition & & & & & & & & & & \\
\hline Incongruent & & & & & & & & & & \\
\hline RT & 653 & 45 & 604 & 47 & 557 & 57 & 559 & 54 & 514 & 52 \\
\hline Accuracy & 96.2 & 2.3 & 97.7 & .9 & 96.5 & 1.7 & 96.7 & 2.0 & 96.8 & 1.7 \\
\hline \multicolumn{11}{|l|}{ Congruent } \\
\hline RT & 637 & 43 & 583 & 48 & 551 & 67 & 512 & 49 & 488 & 50 \\
\hline Accuracy & 96.9 & 1.3 & 97.4 & 2.0 & 99.0 & 1.0 & 97.3 & 1.2 & 97.1 & 1.2 \\
\hline \multicolumn{11}{|c|}{ Session 9} \\
\hline \multicolumn{11}{|l|}{ Task alternation } \\
\hline \multicolumn{11}{|l|}{ Incongruent } \\
\hline RT & 728 & 72 & 659 & 67 & 609 & 70 & 623 & 75 & 581 & 76 \\
\hline Accuracy & 91.9 & 2.0 & 93.5 & 3.1 & 93.6 & 3.1 & 95.4 & 1.7 & 95.2 & 2.5 \\
\hline \multicolumn{11}{|l|}{ Congruent } \\
\hline $\mathrm{RT}$ & 665 & 48 & 619 & 55 & 583 & 75 & 554 & 58 & 542 & 66 \\
\hline Accuracy & 96.2 & 1.3 & 96.1 & 1.7 & 96.6 & 1.6 & 97.4 & .6 & 96.3 & 1.7 \\
\hline \multicolumn{11}{|l|}{ Task repetition } \\
\hline \multicolumn{11}{|l|}{ Incongruent } \\
\hline RT & 698 & 60 & 654 & 83 & 555 & 59 & 555 & 56 & 545 & 55 \\
\hline Accuracy & 97.0 & 1.3 & 97.3 & 1.6 & 96.9 & 1.2 & 95.5 & 3.5 & 97.6 & 1.6 \\
\hline Congruent & & & & & & & & & & \\
\hline $\mathrm{RT}$ & 647 & 55 & 600 & 65 & 533 & 52 & 532 & 55 & 503 & 54 \\
\hline Accuracy & 97.4 & 1.0 & 99.3 & .7 & 98.9 & .7 & 98.9 & .7 & 97.8 & 1.2 \\
\hline Cue repetition & & & & & & & & & & \\
\hline Incongruent & & & & & & & & & & \\
\hline RT & 634 & 43 & 581 & 40 & 550 & 59 & 533 & 55 & 528 & 70 \\
\hline Accuracy & 97.6 & 1.4 & 97.2 & 1.8 & 93.7 & 2.2 & 96.2 & 1.7 & 98.5 & 1.1 \\
\hline Congruent & & & & & & & & & & \\
\hline $\mathrm{RT}$ & 652 & 68 & 585 & 52 & 539 & 55 & 542 & 74 & 515 & 44 \\
\hline Accuracy & 96.6 & 1.5 & 95.3 & 1.8 & 99.1 & .9 & 95.6 & 2.0 & 96.8 & 1.7 \\
\hline & & & & ession & & & & & & \\
\hline Task alternation & & & & & & & & & & \\
\hline Incongruent & & & & & & & & & & \\
\hline $\mathrm{RT}$ & 699 & 64 & 633 & 67 & 591 & 69 & 564 & 62 & 559 & 72 \\
\hline Accuracy & 92.5 & 3.2 & 96.2 & 1.3 & 95.4 & 2.5 & 94.7 & 1.8 & 94.3 & 2.5 \\
\hline Congruent & & & & & & & & & & \\
\hline $\mathrm{RT}$ & 660 & 58 & 600 & 54 & 570 & 67 & 546 & 64 & 546 & 72 \\
\hline Accuracy & 95.0 & 1.7 & 96.0 & 1.1 & 97.2 & 1.5 & 96.4 & 1.1 & 97.8 & 1.5 \\
\hline Task repetition & & & & & & & & & & \\
\hline Incongruent & & & & & & & & & & \\
\hline RT & 663 & 45 & 590 & 43 & 550 & 53 & 603 & 90 & 521 & 47 \\
\hline Accuracy & 98.0 & 1.0 & 96.3 & 2.5 & 96.0 & 2.4 & 95.4 & 1.5 & 98.9 & 1.1 \\
\hline Congruent & & & & & & & & & & \\
\hline RT & 609 & 37 & 584 & 53 & 561 & 74 & 519 & 70 & 522 & 61 \\
\hline Accuracy & 98.6 & .7 & 98.5 & 1.5 & 97.1 & .9 & 96.3 & 1.5 & 97.1 & 1.9 \\
\hline Cue repetition & & & & & & & & & & \\
\hline Incongruent & & & & & & & & & & \\
\hline RT & 629 & 45 & 578 & 47 & 539 & 51 & 529 & 50 & 519 & 52 \\
\hline Accuracy & 94.8 & 3.3 & 96.3 & 1.7 & 95.5 & .9 & 97.5 & 1.2 & 96.8 & 1.6 \\
\hline Congruent & & & & & & & & & & \\
\hline $\mathrm{RT}$ & 633 & 47 & 544 & 40 & 552 & 63 & 516 & 50 & 500 & 28 \\
\hline Accuracy & 96.6 & 1.7 & 96.5 & 1.9 & 96.3 & 2.7 & 96.7 & 1.2 & 97.3 & 2.2 \\
\hline
\end{tabular}

semantic memory and so result in faster cue encoding than task repetitions and task alternations. In the present experiment, episodic memory contributed other runners to the race, and as practice progressed, these other runners came to dominate the race, beating short-term memory and semantic memory traces on most of the trials. Consequently, the transition effects, which reflect the contribution of short-term memory, diminished to the point of disappearing.

It is interesting that the reduction in transition effects with practice was confined to the contrast between cue repetitions and 
Table 6

Analyses of Variance for Mean Reaction Time and Accuracy in Experiment 3

\begin{tabular}{|c|c|c|c|c|c|}
\hline \multirow[b]{2}{*}{ Effect } & \multirow[b]{2}{*}{$d f$} & \multicolumn{2}{|c|}{ Reaction time } & \multicolumn{2}{|c|}{ Accuracy } \\
\hline & & $F$ & $M S E$ & $F$ & $M S E$ \\
\hline Session (E) & 9,63 & $37.18 * *$ & $53,130.55$ & $2.09 *$ & 21.52 \\
\hline Transition (T) & 2,14 & $16.82 * *$ & $63,967.66$ & $9.21 * *$ & 45.18 \\
\hline Cue-target congruency (C) & 1,7 & $76.33^{* *}$ & $14,258.70$ & 2.35 & 558.72 \\
\hline Stimulus onset asynchrony (S) & 4,28 & $55.76^{* *}$ & $48,922.50$ & 0.67 & 14.55 \\
\hline$E \times T$ & 18,126 & $9.82 * *$ & $4,662.81$ & $1.75^{*}$ & 10.60 \\
\hline $\mathrm{E} \times \mathrm{C}$ & 9,63 & $6.86^{* *}$ & $2,933.85$ & 1.72 & 13.99 \\
\hline$E \times S$ & 36,252 & $13.45^{* *}$ & $2,695.84$ & 0.92 & 10.36 \\
\hline $\mathrm{T} \times \mathrm{C}$ & 2,14 & $21.43^{* *}$ & $5,486.85$ & 2.35 & 70.47 \\
\hline $\mathrm{T} \times \mathrm{S}$ & 8,56 & $8.40 * *$ & $4,219.84$ & $2.87 * *$ & 8.03 \\
\hline $\mathrm{C} \times \mathrm{S}$ & 4,28 & $9.38 * *$ & $1,822.97$ & 2.25 & 16.19 \\
\hline $\mathrm{E} \times \mathrm{T} \times \mathrm{C}$ & 18,126 & 1.34 & $2,524.27$ & 1.53 & 8.18 \\
\hline $\mathrm{E} \times \mathrm{T} \times \mathrm{S}$ & 72,504 & $1.45^{*}$ & $2,494.78$ & 0.87 & 10.67 \\
\hline $\mathrm{E} \times \mathrm{C} \times \mathrm{S}$ & 36,252 & $1.57 *$ & $2,524.39$ & 1.07 & 10.43 \\
\hline $\mathrm{T} \times \mathrm{C} \times \mathrm{S}$ & 8,56 & 1.09 & $2,765.95$ & 1.11 & 9.08 \\
\hline $\mathrm{E} \times \mathrm{T} \times \mathrm{C} \times \mathrm{S}$ & 72,504 & 1.17 & $2,348.55$ & 0.82 & 9.92 \\
\hline
\end{tabular}

Note. $* p<.05 . \quad * * p<.01$.

task repetitions. The contrast between task repetitions and task alternations was relatively stable over practice. Mayr and Kliegl (2003) also found that the contrast between task repetitions and task alternations was stable over practice, and they interpreted it as evidence for a dissociation between cue encoding and the instantiation of the mapping rules required to support performance. However, the difference between task repetitions and task alternations is confounded with sequential effects. Task repetitions (like cue repetitions) involve the task sequences $\mathrm{AAA}$ and BAA, whereas task alternations involve the task sequences $\mathrm{ABA}$ and BBA. Several investigators have found longer RT with ABA sequences (Arbuthnott \& Frank, 2000; Mayr \& Keele, 2000), which they interpreted as evidence for task set inhibition. It is possible that the increased RT with ABA sequences is due to other factors, such as residual interference with response selection or changes in decision criteria in response to conflict, and these

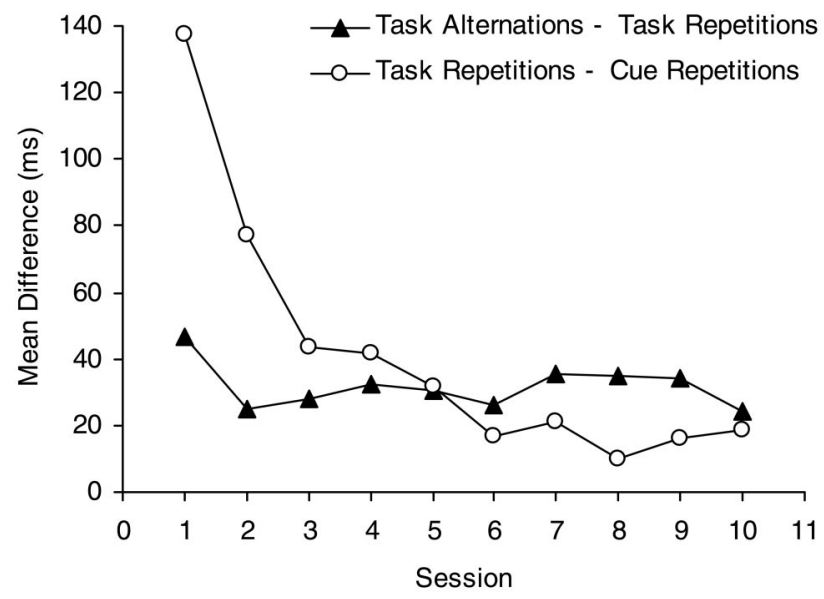

Figure 4. Mean difference between task alternations and task repetitions and between task repetitions and cue repetitions as a function of session in Experiment 3. Fisher's least significant difference for $p<.05$ is $21 \mathrm{~ms}$. effects may not decrease with practice. Thus, the interpretation of the stability of the difference between task alternations and task repetitions over practice remains uncertain.

\section{Conclusions}

This experiment showed a reduction in the congruency effect with extended practice, suggesting that mediator retrieval may be replaced by direct associations between cues and targets, even if the cues are not completely transparent.

\section{General Discussion}

Each experiment provided evidence that subjects used mediators to deal with nontransparent cues in the explicit task-cuing procedure. The evidence was in the form of a congruency effect, in

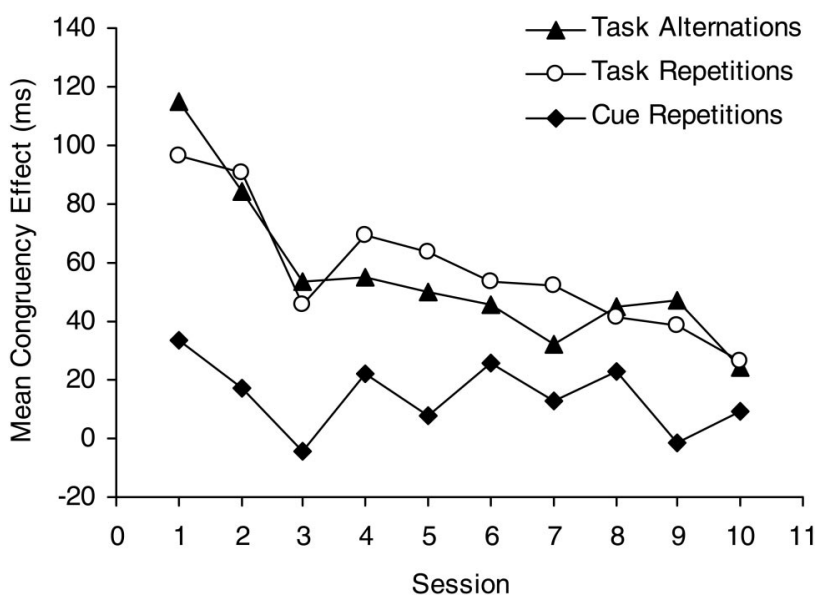

Figure 5. Mean cue-target congruency effect for each transition as a function of session in Experiment 3. Fisher's least significant difference for $p<.05$ is $22 \mathrm{~ms}$. 
which RT was faster if the word associated with the cue was congruent with the target (e.g., $O D D-3$ ) than if it was incongruent (e.g., $O D D-4$ ). Experiment 1 showed this congruency effect with the word cues $O D D, E V E N, H I G H$, and $L O W$, replicating Schneider and Logan (2005), and with the relatively transparent letter cues $O, E, H$, and $L$. The congruency effect with nontransparent letter cues $D, V, G$, and $W$ was negligible. Experiment 2 showed that the congruency effect depended on subjects' knowledge of the relations between cues and mediating words. Subjects trained on $D, V, G$, and $W$ showed no congruency effect until they were told of the relations between cues and words halfway through the experiment, whereupon they showed strong congruency effects. Experiment 3 examined the role of extended practice on mediator retrieval, finding that mediators tended to drop out as practice progressed. The congruency effect diminished substantially over the course of 10 sessions. The congruency effects in all three experiments suggest that subjects used mediators with nontransparent cues, which supports the mediated retrieval hypothesis and challenges the association strength hypothesis.

\section{Cue Interpretation and Target Processing}

The researchers who compared transparent and nontransparent cues provided accounts of performance that differ in two respects: in terms of their assumptions about cue interpretation and in terms of their assumptions about how the target is processed after the cue is interpreted. With respect to cue interpretation, Arbuthnott and Woodward (2002) and Miyake et al. (2004) assumed that transparent and nontransparent cues differ in terms of their strength of association with task goals or task sets, whereas Logan and Bundesen (2004) and Mayr and Kliegl (2000) assumed that nontransparent cues require mediator retrieval. The results of the present experiments challenge the position taken by Arbuthnott and Woodward and Miyake et al. and support the position taken by Logan and Bundesen (2004) and Mayr and Kliegl. With respect to target processing, Arbuthnott and Woodward and Mayr and Kliegl assumed that cues retrieve the mapping rules required to support performance, and the instantiation of these rules in the processing system constitutes the reconfiguration required for task switching. By contrast, Logan and Bundesen (2004) and Miyake et al. assumed that cues retrieve goals and goal retrieval is sufficient to enable accurate performance. Logan and Bundesen (2004) took a stronger position than did Miyake et al., assuming that the cue and the target are put together to form a compound retrieval cue that pulls the correct response from semantic memory. There is no reconfiguration. The task set is the same whether or not the task repeats: subjects encode the cue, encode the target, and respond with whatever they retrieve from semantic memory. Switch costs reflect benefits in cue encoding that result from repeating the cue (see also Arrington \& Logan, 2004b; Logan \& Bundesen, 2003; Logan \& Schneider, in press; Schneider \& Logan, 2005, in press).

The present results do not address the contrast between these positions on target processing directly, but previous results with a similar procedure are relevant. Schneider and Logan (2005) tested the idea that cues retrieve mapping rules by presenting word cues in positions that were spatially compatible or spatially incompatible with the response mapping. Subjects who mapped odd and high onto the left key and low and even onto the right key were presented with the cues ODD-EVEN, HIGH-LOW, EVEN-ODD, and $L O W-H I G H$. The first two cues were compatible with the response mapping, and the last two cues were incompatible with it. If subjects relied on the cues to provide the mapping rules, performance should be much better with compatible cues than with incompatible cues, yet the compatibility effect was only $24 \mathrm{~ms}$ and did not interact with other factors in the experiment, including SOA, transition, and cue-target congruency. This suggests that subjects did not use the cues to retrieve mapping rules, which is consistent with the position taken by Logan and Bundesen (2004) and Miyake et al. (2004) and inconsistent with the position taken by Mayr and Kliegl (2000) and Arbuthnott and Woodward (2002). Thus, the present results and the previous ones are more consistent with Logan and Bundesen's (2004) position on cue interpretation and target processing than with the positions taken by other researchers.

\section{Toward a Model of Mediation}

It should be possible to extend our formal model of the explicit task-cuing procedure to encompass mediator retrieval (Schneider \& Logan, 2005). We created a mathematical model and a computer simulation that takes words and digits as inputs and selects appropriate responses with acceptable levels of accuracy and with RTs that closely resemble those of human subjects. The model assumes that subjects use words and digits as compound retrieval cues that retrieve response categories from semantic memory, so $O D D$ and 3 retrieve odd. The model dealt with transparent cues, but it should be easy to extend it to deal with nontransparent cues. As we have suggested, subjects may retrieve words as mediators in response to nontransparent cues and then combine these mediators with targets to form compound retrieval cues, which then retrieve the appropriate response from memory.

The model produces congruency effects with transparent word cues and the same mechanisms should produce congruency effects with the mediators retrieved from nontransparent cues. The model assumes that the presentation of a word or the retrieval of a mediator activates a strong representation of itself in working memory. It also activates weaker representations of other words that are associated with it. Thus, $O D D$ activates odd strongly and even weakly. These activated representations of the words combine multiplicatively with the activated representation of the target and jointly determine the drift rate of a random-walk retrieval process that selects a response category, like odd or even. If the presented word is congruent with the target, the drift rate for the correct response is higher, so RT is faster and accuracy is higher. If the presented word is incongruent with the target, the drift rate for the correct response is lower, so RT is slower and accuracy is lower.

The extended model provides some leverage against an alternative interpretation of our results, in which words and mediators do not participate in the decision process directly but instead produce a kind of Stroop-like interference by activating response categories unintentionally. In our model, the words play a direct causal role in the retrieval process and the congruency effects directly reflect the role they play. Our simulations and modeling show that this role is sufficient to account for the details of performance, but they do not prove that it is necessary. We suggest that advocates of the alternative point of view, that words play only an incidental role in the retrieval process, should produce a competing model based on 
that hypothesis that accounts for the data as well as or better than the model we have proposed.

\section{Mediator Retrieval in Other Task Switching Procedures}

Our experiments have implications for other task switching procedures that do not provide explicit instructional cues. For example, Jersild's (1927) alternating tasks procedure requires subjects to keep track of the task to be performed on their own, Arrington and Logan's (2004a) voluntary task switching procedure requires subjects to generate the task to be performed on their own, and Logan's (2004) task span procedure requires subjects to keep the list of tasks to be performed in memory. We suggest that subjects use words as mediators in each of these procedures and put the mediators together with the targets to form compound retrieval cues that pull the required response from memory.

Rogers and Monsell's (1995) alternating runs procedure is an intermediate case. On the one hand, the sequence of tasks is predictable, so subjects can use memory to determine which task to perform on a given trial. On the other hand, tasks are usually associated with locations, so location may serve as an arbitrary cue. Mediators may play a role from both of these perspectives. Subjects may rehearse a predictable sequence of mediators to keep track of the task to be performed and combine the current mediator with the current target to pull the appropriate response from memory. Also, subjects may use location to retrieve the relevant mediator, which they then combine with the target to pull the appropriate response from memory.

Articulatory suppression may provide converging evidence for mediator retrieval in a number of task switching procedures. Articulatory suppression interferes selectively with articulatory representations, and subjects may use articulatory representations to retrieve and maintain mediators (Goschke, 2000). Baddeley, Chincotta, and Adlam (2001) and Emerson and Miyake (2003) found that articulatory suppression inflated switch costs in the alternating tasks procedure, which would be expected if subjects had to retrieve a new mediator on task alternation trials. Miyake et al. (2004) found that articulatory suppression inflated switch costs more for relatively transparent cues (the first letter of each task name) than for completely transparent cues (the task names) in the explicit task-cuing procedure, which is consistent with our mediator hypothesis.

\section{Language and Cognitive Control}

Ultimately, the significance of our experiments lies in the implications they have for the role of language in cognitive control. All of our social institutions depend on the ability of people to instruct others to do things. This ability is relevant to many domains in psychology, ranging from studies of the instrumental or pragmatic use of language in psycholinguistics to studies of obedience and conformity in social psychology. From a practical perspective, the ability to instruct others to do things is an essential ingredient of human experimental psychology. Five minutes of verbal instructions can put a human in a state of preparation to perform a task that would take 5 months of training to establish in a monkey (Roepstorff \& Frith, 2004).

It may be possible to make some headway in understanding how people understand instructions without solving all of the problems of language comprehension and social influence by studying simpler situations in which people already have some idea of what to do. Psychology experiments may be good examples of these simpler situations, and task-switching experiments with explicit cues may provide some insight into the issues involved in comprehending experimental instructions. Our experiments on mediator retrieval suggest that subjects interpret cues by relating them to knowledge they already possess about what to do and how to do it With this knowledge, the cues can reduce the amount of language comprehension that is necessary to adopt a particular task set. Indeed, the subjects in our experiments already knew which digits were odd and even and which digits were greater or less than 5 before they came to the laboratory. Brief verbal instructions and simple cues were all that were required to induce them to bring this knowledge to bear on the tasks with which we presented them. From this perspective, our mediator retrieval hypothesis may be viewed as the core process in interpreting instructions, which must be elaborated in more complex or less familiar situations.

The ability to understand instructions from others is also relevant to the ability to control one's own thoughts and actions. Luria (1961) and Vygotsky (1934/1986) suggested that children acquire the ability to control themselves through inner speech by internalizing the processes involved in having their behavior controlled by instructions from others. Simple cues like those in our experiments may be all that is required in self-control. People trying to control themselves already have extensive knowledge of what they intend to do and how they intend to do it. Simple cues like the single words in our experiments may be sufficient to activate all of the knowledge they need to perform the tasks they intend to do.

\section{References}

Arbuthnott, K. D., \& Frank, J. (2000). Executive control in set switching: Residual switch cost and task-set inhibition. Canadian Journal of Experimental Psychology, 54, 33-41.

Arbuthnott, K. D., \& Woodward, T. S. (2002). The influence of cue-task association and location on switch cost and alternating switch cost. Canadian Journal of Experimental Psychology, 56, 18-29.

Arrington, C. M., \& Logan, G. D. (2004a). The cost of a voluntary task switch. Psychological Science, 15, 610-615.

Arrington, C. M., \& Logan, G. D. (2004b). Episodic and semantic components of the compound stimulus strategy in the explicit task-cuing procedure. Memory \& Cognition, 32, 965-976.

Baddeley, A. D., Chincotta, D., \& Adlam, A. (2001). Working memory and the control of action: Evidence from task switching. Journal of Experimental Psychology: General, 130, 641-657.

Emerson, M. J., \& Miyake, A. (2003). The role of inner speech in task switching: A dual-task investigation. Journal of Memory and Language, $48,148-168$

Goschke, T. (2000). Intentional reconfiguration and involuntary persistence in task set switching. In S. Monsell \& J. Driver (Eds.), Attention \& performance XVIII: Control of cognitive processes (pp. 331-356). Cambridge, MA: MIT Press.

Jersild, A. T. (1927). Mental set and shift. Archives of Psychology, 14(Whole No. 89), 5-82.

Logan, G. D. (1988). Toward an instance theory of automatization. Psychological Review, 95, 492-527.

Logan, G. D. (2003). Executive control of thought and action: In search of the wild homunculus. Current Directions in Psychological Science, 12, $45-48$.

Logan, G. D. (2004). Working memory, task switching, and executive 
control in the task span procedure. Journal of Experimental Psychology: General, 133, 218-236.

Logan, G. D., \& Bundesen, C. (2003). Clever homunculus: Is there an endogenous act of control in the explicit task-cuing procedure? Journal of Experimental Psychology: Human Perception and Performance, 29, $575-599$.

Logan, G. D., \& Bundesen, C. (2004). Very clever homunculus: Compound stimulus strategies for the explicit task-cuing procedure. Psychonomic Bulletin \& Review, 11, 832-840.

Logan, G. D., \& Schneider, D. W. (in press). Priming or executive control? Associative priming of cue encoding increases "switch costs" in the explicit task-cuing procedure. Memory \& Cognition.

Luria, A. R. (1961). The role of speech in the regulation of normal and abnormal behavior. New York: Liveright.

Mayr, U., \& Keele, S. W. (2000). Changing internal constraints on action: The role of backward inhibition. Journal of Experimental Psychology: General, 129, 4-26.

Mayr, U., \& Kliegl, R. (2000). Task-set switching and long-term memory retrieval. Journal of Experimental Psychology: Learning, Memory, and Cognition, 26, 1124-1140.

Mayr, U., \& Kliegl, R. (2003). Differential effects of cue changes and task changes on task-set selection costs. Journal of Experimental Psychology: Learning, Memory, and Cognition, 29, 362-372.

Miyake, A., Emerson, M. J., Padilla, F., \& Ahn, J.-C. (2004). Inner speech as a retrieval aid for task goals: The effects of cue type and articulatory suppression in the random task cuing paradigm. Acta Psychologica, 115, 123-142.

Monsell, S. (2003). Task switching. Trends in Cognitive Sciences, 7 , 134-140.

Psychology Software Tools. (2002). E-Prime (Version 1.1) [Computer software]. Pittsburgh, PA.

Roepstorff, A., \& Frith, C. (2004). What's at the top in the top-down control of action? Script-sharing and 'top-top' control of action in cognitive experiments. Psychological Research, 68, 189-198.

Rogers, R. D., \& Monsell, S. (1995). The cost of a predictable switch between simple cognitive tasks. Journal of Experimental Psychology: General, 124, 207-231.

Schneider, D. W., \& Logan, G. D. (2005). Modeling task switching without switching tasks: A short-term priming account of explicitly cued performance. Journal of Experimental Psychology: General, 134, 343-367.

Schneider, D. W., \& Logan, G. D. (in press). Priming cue encoding by manipulating transition frequency in explicitly cued task switching. Psychonomic Bulletin \& Review.

Vygotsky, L. (1986). Thought and language (A. Kozulin, Trans.). Cambridge, MA: MIT Press (Original work published 1934)

Received June 10, 2005

Revision received September 10, 2005

Accepted November 14, 2005

\section{ORDER FORM}

\section{Start my 2006 subscription to Journal of Experimental \\ Psychology: Learning, Memory, and Cognition! ISSN: 0278-7393}

\section{- \$144.00, APA Member/AfFiliate $\$ 301.00$, INDIVIdUAL NoNMEMbER $\$ 759.00$, INSTITUTION In DC add 5.75\% / In MD add 5\% sales tax} Total Amount Enclosed

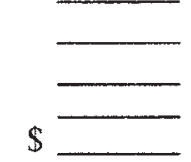

Subscription orders must be prepaid. (Subscriptions are on a calendar year basis only.) Allow 4-6 weeks for delivery of the first issue. Call for international subscription rates.

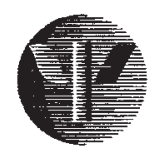

AMERICAN PSYCHOLOGICAL ASSOCIATION

\section{SEND THIS ORDER FORM TO:}

American Psychological Association

Subscriptions

750 First Street, NE

Washington, DC 20002-4242

Or call 800-374-2721, fax 202-336-5568.

TDD/TTY 202-336-6123.

For subscription information, e-mail:

subscriptions@apa.org
Send me a FREE Sample Issue

Check enclosed (make payable to APA)

Charge my: VISA MasterCard American

Express

Cardholder Name

Card No. Exp. Date

Signature (Required for Charge)

BILLING ADDRESS:

Street

City

State

Zip

Daytime Phone

E-mail

MAIL TO:

Name

Address

City

State

Zip

APA Member \# 